\title{
Validation and
}

Calibration of Nuclear

Thermal Hydraulics

Multiscale Multiphysics

Models - Subcooled

Flow Boiling Study

Anh Bui

Nam Dinh

Brian Williams

September 2013

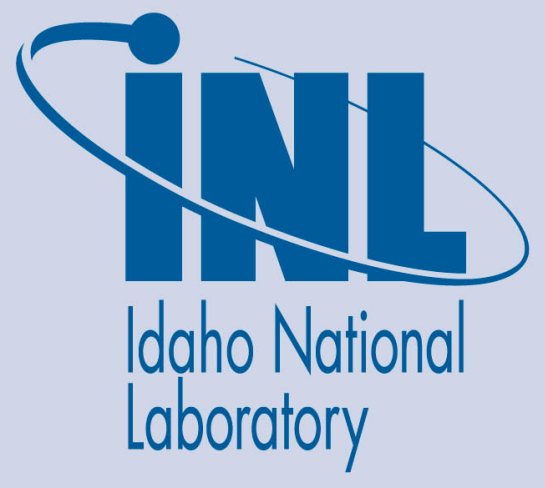

The INL is a U.S. Department of Energy National Laboratory operated by Battelle Energy Alliance 
INL/EXT-13-30293

\title{
Validation and Calibration of Nuclear Thermal Hydraulics Multiscale Multiphysics Models - Subcooled Flow Boiling Study
}

\author{
Anh Bui \\ Nam Dinh ${ }^{1}$ \\ Brian Williams ${ }^{2}$ \\ ${ }^{1}$ North Carolina State University \\ ${ }^{2}$ Los Alamos National Laboratory
}

September 2013

Idaho National Laboratory
Idaho Falls, Idaho 83415

http://www.inl.gov

Prepared for the

U.S. Department of Energy

Office of Nuclear Energy

Under DOE Idaho Operations Office

Contract DE-AC07-05ID14517 

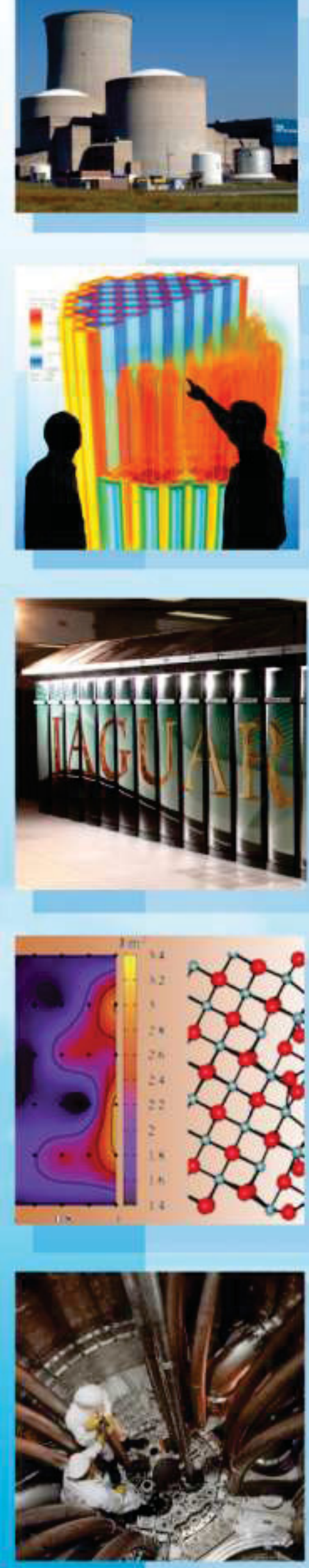

Engineering design and analysis

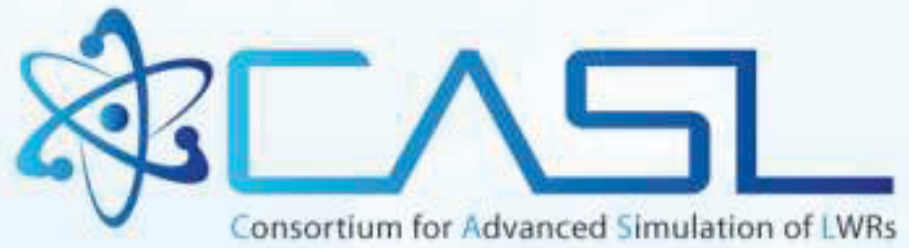

Validation and Calibration of Nuclear Thermal Hydraulics Multiscale Multiphysics Models - Subcooled Flow Boiling Study Science-enabling high performance computing

\section{Anh Bui Idaho National Laboratory \\ Nam Dinh}

Fundamental science North Carolina State University Brian Williams

Los Alamos National Laboratory September 30, 2013

Plant operational data 
REVISION LOG

\begin{tabular}{|l|l|l|l|}
\hline Revision & Date & Affected Pages & Revision Description \\
\hline & & & \\
\hline & & & \\
\hline & & & \\
\hline & & & \\
\hline
\end{tabular}

\section{Document pages that are:}

Export Controlled

IP/Proprietary/NDA Controlled

Sensitive Controlled

\section{Requested Distribution:}

To:

Doug Kothe, CASL Director

Douglas Burns, CASL Deputy Director

Paul Turinsky, CASL Chief Scientist

Jeff Banta, CASL Program Manager

Copy:

Vincent Mousseau, VUQ/SNL

Brian Williams, VUQ/LANL

Yixing Sung, AMA/WEC

Matt Sieger, QM/ORNL

Mark Christon, THM/LANL

Emilio Baglietti, THM/MIT

Jess Gehin, AMA/ORNL

Zeses Karoutas, AMA/WEC

Jeffrey Secker, AMA/WEC 


\section{DISCLAIMER}

This information was prepared as an account of work sponsored by an agency of the U.S. Government. Neither the U.S. Government nor any agency thereof, nor any of their employees, makes any warranty, expressed or implied, or assumes any legal liability or responsibility for the accuracy, completeness, or usefulness, of any information, apparatus, product, or process disclosed, or represents that its use would not infringe privately owned rights. References herein to any specific commercial product, process, or service by trade name, trade mark, manufacturer, or otherwise, does not necessarily constitute or imply its endorsement, recommendation, or favoring by the U.S. Government or any agency thereof. The views and opinions of authors expressed herein do not necessarily state or reflect those of the U.S. Government or any agency thereof.

While every effort has been made to ensure correctness of the findings in this report, minor mistakes are inevitable when assimilating and transcribing such a large volume of material. These errors are unintentional and apologies are extended where needed. Corrections are welcome to ensure accuracy of the findings. 


\section{ABSTRACT}

In addition to a validation data plan for quantification of data needs and strategy for data collection and characterization [1] [2], development of advanced techniques for calibration and validation of complex multiscale, multiphysics nuclear reactor simulation codes are a major component of the CASL VUQ plan.

Advanced modeling of LWR systems normally involves a range of physicochemical models describing multiple interacting phenomena, such as thermal hydraulics, reactor physics, coolant chemistry, etc., which occur over a wide range of spatial and temporal scales. To a large extent, the accuracy of (and uncertainty in) overall model predictions is determined by the correctness of various sub-models, which are not conservation-laws based, but empirically derived from measurement data. Such sub-models normally require extensive calibration before the models can be applied to analysis of real reactor problems.

This work demonstrates a case study of calibration of a common model of subcooled flow boiling, which is an important multiscale, multiphysics phenomenon in LWR thermal hydraulics. The calibration process is based on a new strategy of model-data integration, in which, all sub-models are simultaneously analyzed and calibrated using multiple sets of data of different types. Specifically, both data on large-scale distributions of void fraction and fluid temperature and data on smallscale physics of wall evaporation were simultaneously used in this work's calibration.

In a departure from traditional (or common-sense) practice of tuning/calibrating complex models, a modern calibration technique based on statistical modeling and Bayesian inference was employed, which allowed simultaneous calibration of multiple sub-models (and related parameters) using different datasets. Quality of data (relevancy, scalability, and uncertainty) could be taken into consideration in the calibration process.

This work presents a step forward in the development and realization of the CIPS Validation Data Plan [3] [1] at the Consortium for Advanced Simulation of LWRs to enable quantitative assessment of the CASL modeling of Crud-Induced Power Shift (CIPS) phenomenon, in particular, and the CASL advanced predictive capabilities, in general.

This report is prepared for the Department of Energy's Consortium for Advanced Simulation of LWRs program's VUQ Focus Area. 


\section{EXECUTIVE SUMMARY}

This milestone supports a case study of calibration and validation of a realistic and relatively complex subcooled flow boiling model, with the objective to develop recommendations on CASL-wide Model Calibration, Validation, and Uncertainty Quantification efforts. The SFB model utilized a common description of multiphase flow as inter-penetrating continua with conservation laws applied to each phase as a separate field. Small-scale physics related to thermal hydrodynamic inter-phase and flow-wall interactions were represented by various empirical/semi-empirical closure sub-models. In this SFB modeling, the sub-model of wall evaporation, which relied on mechanistic descriptions of bubble growth/departure and wall nucleation, was selected for calibration.

In a departure from traditional (or common-sense) practice of tuning/calibrating complex models, a modern calibration technique based on statistical modeling and Bayesian inference was employed, which allowed simultaneous calibration of multiple sub-models (and related parameters) using different datasets. Quality of data (relevancy, scalability, and uncertainty) could be taken into consideration in the calibration process.

The proposed calibration technique would need tens thousands of model evaluations, which makes direct simulations by the original physical model impractical in many cases. This study demonstrated that a computationally less expensive surrogate (emulator) of the SFB model with multidimensional and multivariate outputs could successfully be built using PCA, Gaussian processes, and process convolution method.

In a recognition of the heterogeneity of available validation data ("data realism" concept), effort was made to investigate the possibility of simultaneous assimilation/integration of different data types in complex model analysis. As demonstrated in this study, multidimensional/ multivariate data on large-scale distributions could be used in conjunction with data of small-scale physics for improved model calibration/validation in this preliminary realization of "total data-model integration" (TDMI) concept.

This exercise on SFB model development and implementation/application of advanced model calibration/validation method can potentially benefit CASL, because

- SFB is an important aspect of nuclear reactor thermal hydraulics and its accurate modeling is the objective of several CASL advanced simulation capabilities, such as COBRA-TF and Hydra-TH multiphase;

- CVUQ of CASL complex multiscale, multiphysics modeling capabilities can not purely rely on "traditional" techniques and there is a need for new approach which can leverage on all available data, account for validation data heterogeneity/ availability/quality, and provide a quantification of prediction uncertainty.

This works again emphasizes the importance of the CASL Validation Data Plan and its realization to the CASL-wide CVUQ efforts, which entails, in particular:

- A comprehensive analysis of needs and collection and characterization requirements for CASL validation data;

- Establishment of a central validation database for warehousing of data from various sources (e.g. PIV, TC, imaging, SETs, IETs, DNSs, etc.), concerning various physics and scales (neutronics, thermal hydraulics, fuel behavior, structural mechanics), in different formats (table data, empirical correlations, etc.), and with estimates of measurement errors and uncertainty; 


\section{CONTENTS}

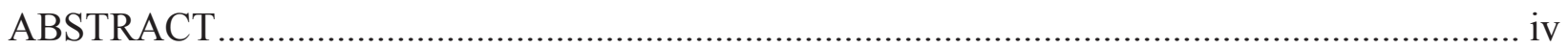

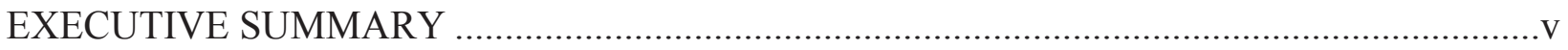

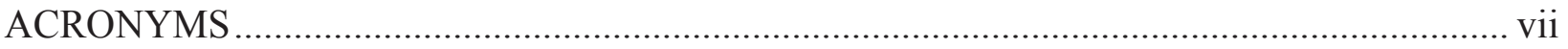

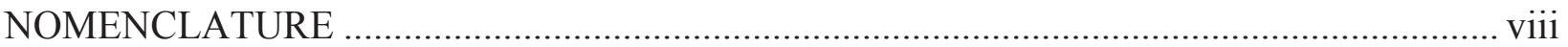

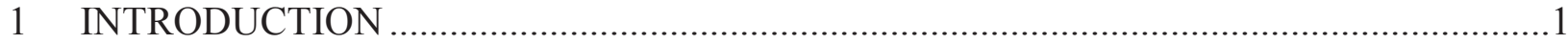

2 OVERVIEW OF SUBCOOLED FLOW BOILING MODELING -

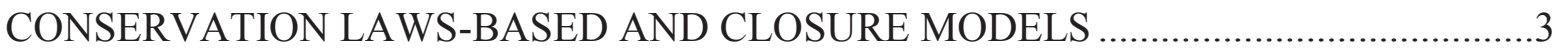

2.1 Conservation Laws-Based Models of Two-Phase Flow .......................................................5

2.2 Closure Laws for Modeling of Subcooled Flow Boiling …..............................................

2.3 Sensitivity of boiling model predictions to closure model parameters and model

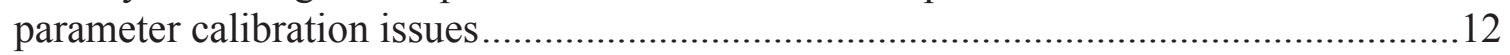

3 CALIBRATION AND VALIDATION OF SUBCOOLED FLOW BOILING

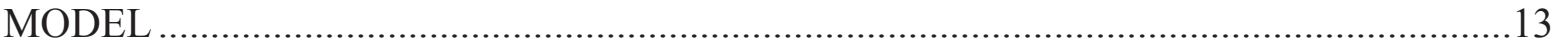

3.1 An Overview of Calibration, Validation, and Uncertainty Quantification (CVUQ) of CASL Advanced Modeling \& Simulation Capabilities.................................................13

3.2 Validation data support for subcooled flow boiling modeling ...........................................15

3.3 Calibration of Subcooled Flow Boiling Model Using Multivariate Heterogeneous Data

3.3.1 Construction of a Multivariate Model Surrogate with Gaussian Processes,

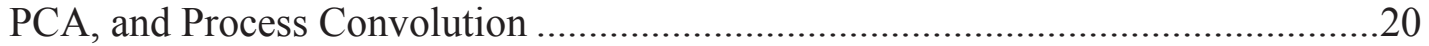

3.3.2 Model Calibration and Validation with GPM/SA ..............................................22

3.3.3 Calibration of SFB Model with Void Fraction and Fluid Temperature Data

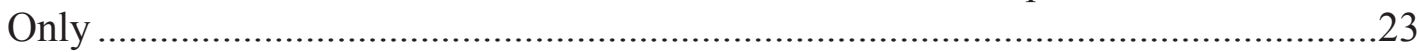

3.3.4 Calibration of SFB Model with Additional Data on Microphysics of Bubble

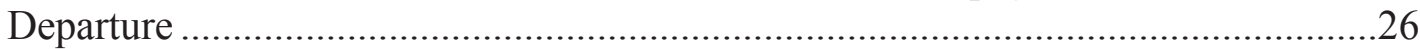

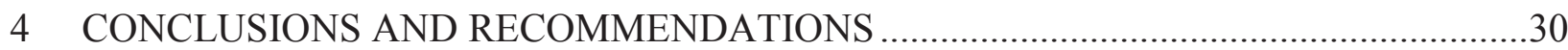

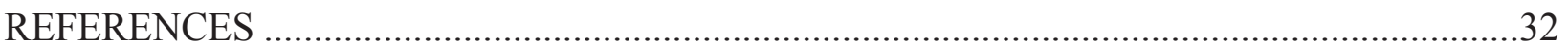




\section{ACRONYMS}

\begin{tabular}{|l|l|}
\hline & Description \\
\hline 1D/2D/3D & One-/Two-/Three-Dimensional \\
\hline AMS & Advanced Modeling and Simulation \\
\hline CASL & Consortium for Advanced Simulations of LWRs \\
\hline CDC & CASL Validation Data Center \\
\hline CFD & Computational Fluid Dynamics \\
\hline CHF & Critical Heat Flux \\
\hline CIPS & Crud Induced Power Shift \\
\hline CMFD & Computational Multi-phase Fluid Dynamics \\
\hline CRUD & Chalk River Unidentified Deposit \\
\hline CVUQ & Calibration, Validation \& Uncertainty Quantification \\
\hline DA & Data Assimilation \\
\hline DAKOTA & $\begin{array}{l}\text { Design Analysis Kit for Optimization and Terascale } \\
\text { Applications }\end{array}$ \\
\hline DNB & Departure from Nucleate Boiling \\
\hline DNS & Direct Numerical Simulation \\
\hline FA & Focus Area (in CASL) \\
\hline GP & Gaussian Process \\
\hline GPMSA & Gaussian Process for Model Sensitivity Analysis \\
\hline GTRF & Grid To Rod Fretting \\
\hline IET & Integral Effect Test \\
\hline LANL & Los Alamos National Laboratory \\
\hline LWR & Light Water Reactor \\
\hline MCMC & Markov Chain Monte Carlo sampling \\
\hline MIT & Massachusetts Institute of Technology \\
\hline ONB & Onset of Nucleate Boiling \\
\hline OSV & Onset of Significant Void \\
\hline PCA & Principal Component Analysis \\
\hline PDE & Partial Differential Equation \\
\hline PIV & Particle Image Velocimetry \\
\hline SET & Separate Effect Test \\
\hline SFB & Subcooled Flow Boiling \\
\hline SNL & Sandia National Laboratory \\
\hline TC & Thermocouple \\
\hline TDMI & Total Data Model Integration \\
\hline THM & Thermal-Hydraulics Method (FA) \\
\hline VDP & Validation Data Plan \\
\hline V\&V & Verification and Validation \\
\hline VERA(-CS) & $\begin{array}{l}\text { Virtual Environment for Reactor Applications (-Core } \\
\text { Simulator components) }\end{array}$ \\
\hline VUQ & Validation \& Uncertainty Quantification \\
\hline UQ & Uncertainty Quantification \\
\hline & \\
\hline
\end{tabular}




\section{NOMENCLATURE}

\begin{tabular}{|c|c|}
\hline \multicolumn{2}{|l|}{ Latin $l$} \\
\hline$a_{i}$ & Interfacial area \\
\hline$a$ & Thermal diffusivity \\
\hline$C_{p}$ & Heat capacity \\
\hline$D_{b}$ & Bubble diameter \\
\hline$D_{d}$ & Bubble departure diameter \\
\hline$D_{h}$ & Hydraulic diameter \\
\hline$f_{d}$ & Bubble departure frequency \\
\hline $\mathrm{Ja}$ & Jakob number \\
\hline$k$ & Fluid turbulent kinetic energy or Heat conductivi \\
\hline$M$ & Interfacial momentum transfer/force \\
\hline$g$ & Gravity \\
\hline$h$ & Enthalpy or Heat transfer coefficient \\
\hline$N_{a}$ & Active nucleation site density \\
\hline$p$ & Pressure \\
\hline $\operatorname{Pr}$ & Prandtl number \\
\hline$q$ & Wall heat flux \\
\hline$R$ & Ideal gas constant \\
\hline$R_{c}$ & Cavity radius \\
\hline $\operatorname{Re}$ & Reynolds number \\
\hline$t$ & Time \\
\hline$T$ & Temperature \\
\hline$\Delta T_{\text {sat }}$ & Superheat of liquid layer under bubble \\
\hline$\Delta T_{s u b}$ & Fluid subcooling $\left(=T_{s}-T_{f}\right)$ \\
\hline$\Delta T_{w}$ & Wall superheat $\left(=T_{w}-T_{s}\right)$ \\
\hline$u$ & Velocity \\
\hline$x_{e q}$ & Equilibrium quality \\
\hline We & Weber number \\
\hline \multicolumn{2}{|c|}{ Greek letters } \\
\hline$\alpha$ & Volume fraction \\
\hline$\beta$ & Half of cavity cone angle \\
\hline$\varepsilon$ & Dissipation rate of fluid turbulent energy \\
\hline$\mu$ & Dynamic viscosity \\
\hline$\theta$ & Contact angle \\
\hline$\rho$ & Density \\
\hline$\Delta \rho$ & Liquid-gas density difference \\
\hline$\sigma$ & Surface tension \\
\hline$\tau$ & Stress tensor \\
\hline$\Gamma$ & Interfacial mass transfer rate \\
\hline
\end{tabular}




\section{Superscripts}

$T$

Subscripts

$b$

$c$

$\mathrm{cr}$

$f$

$f g$

$g$

$i$

$r$

$S$

w
Turbulent

bubble

carrier phase

critical

fluid

transition from fluid to gas

vapor

interfacial

relative

saturated

wall 



\section{INTRODUCTION}

The Consortium for Advanced Simulations of Light-Water Reactors (CASL) in its effort to address the design, operational and safety challenges for LWRs is developing, integrating, and coupling a suite of robust simulation tools, which can model all interacting facets of LWR physics, including core neutronics, reactor thermal hydraulics, fuel performance, structural mechanics, etc., and simulate real-world nuclear reactor problems with high accuracy and fidelity. Rigorous verification and validation (V\&V) of these complex simulation tools as well as quantification and control of prediction uncertainty are seen as important and challenging tasks, which have been clearly defined in the CASL mission and goals.

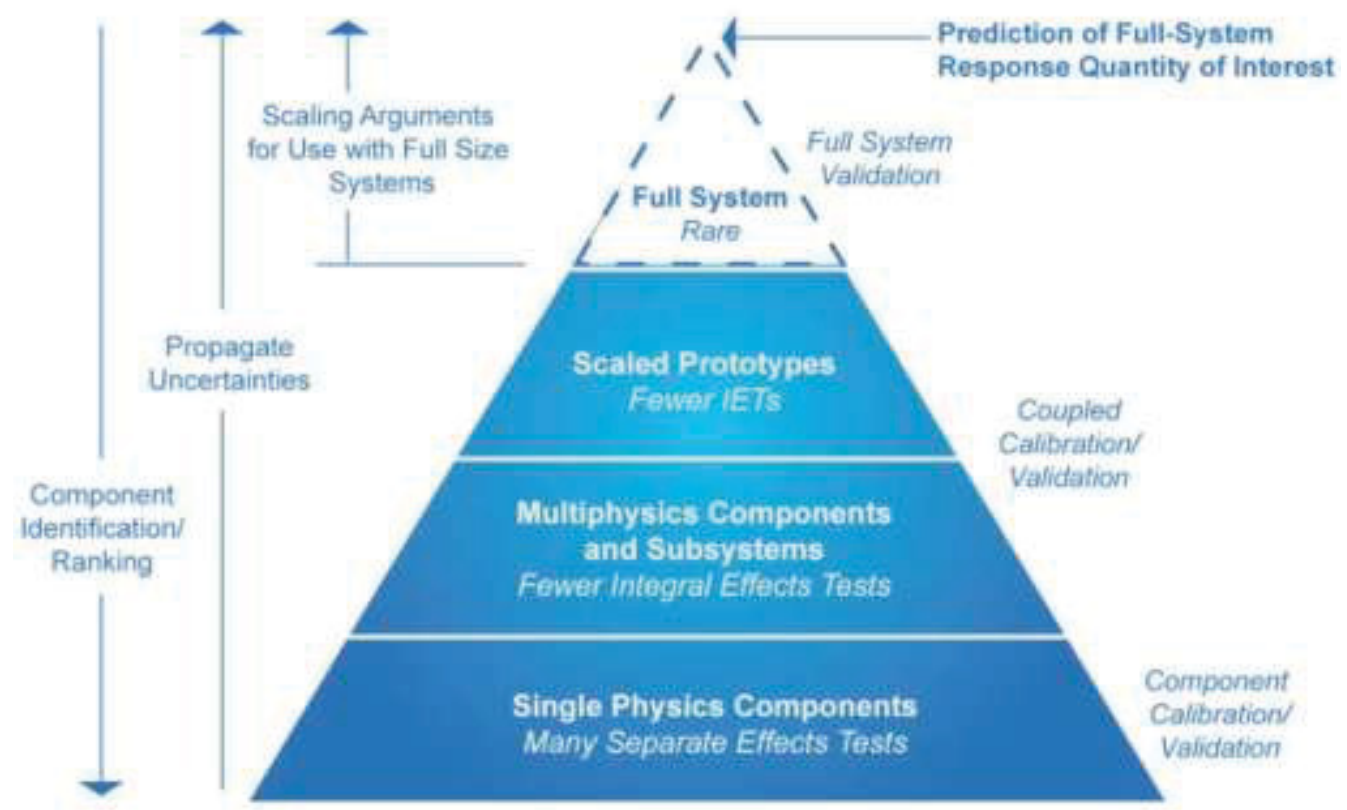

Figure 1.1. CASL vision on complex multiscale, multiphysics model calibration and validation [4].

Several operational and safety challenge problems have been selected for the application and verification of the CASL advanced modeling and simulation technology, which are defined to be important and impactful issues to nuclear energy industry and, at the same time, amenable to modeling \& simulation. Subcooled flow boiling (SFB) is one crucial thermalhydraulic phenomenon which takes place in the CRUD-Induced Power Shift (CIPS) (Figure 1.2) and Departure from Nucleate Boiling (DNB) challenge problems.

Subcooled flow boiling, while being only a heat transfer mode in LWRs and one aspect of CIPS, is by itself characterized by complex couplings and interactions between different thermal hydrodynamic processes happening at different scales with phase transition involved (as shown in Figure 1.2 and Figure 1.3). Modeling of such a multiscale, multiphysics problem would have to address various uncertainty related to a lack of or incomplete understanding about many important underlying small-scale physics and physics couplings and a necessity to describe them in an approximate manner using various data-dependent closure laws/models. The low universality of such crude and approximate representations of physics via data-dependent closure models greatly restricts model applicability and imposes a 


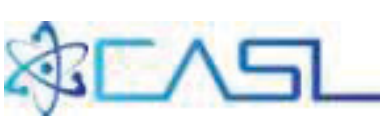

significant burden on model calibration and validation when the model is applied to the analysis of various real-world problems/scenarios.

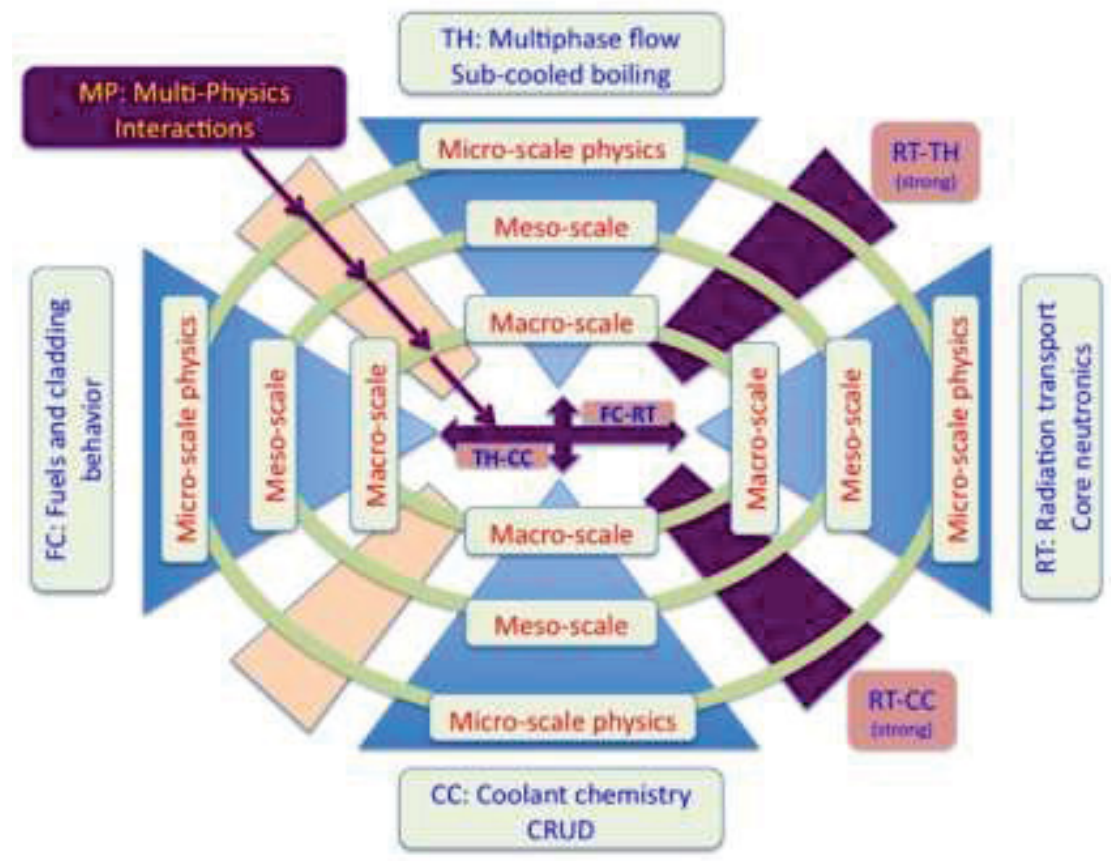

Figure 1.2. CIPS and Subcooled Flow Boiling (SFB) [1].

A common practice for calibration of a computer model is based on a simple realization of "data assimilation", i.e. adjusting control parameters of closure models, previously derived from data, to make them work for a new problem. Until recently, model validation is still based on direct comparison of simulation results and experimental data, which does not allow a quantification of model prediction uncertainty and/or identifying the factors or sub-models which contribute the most to this uncertainty.

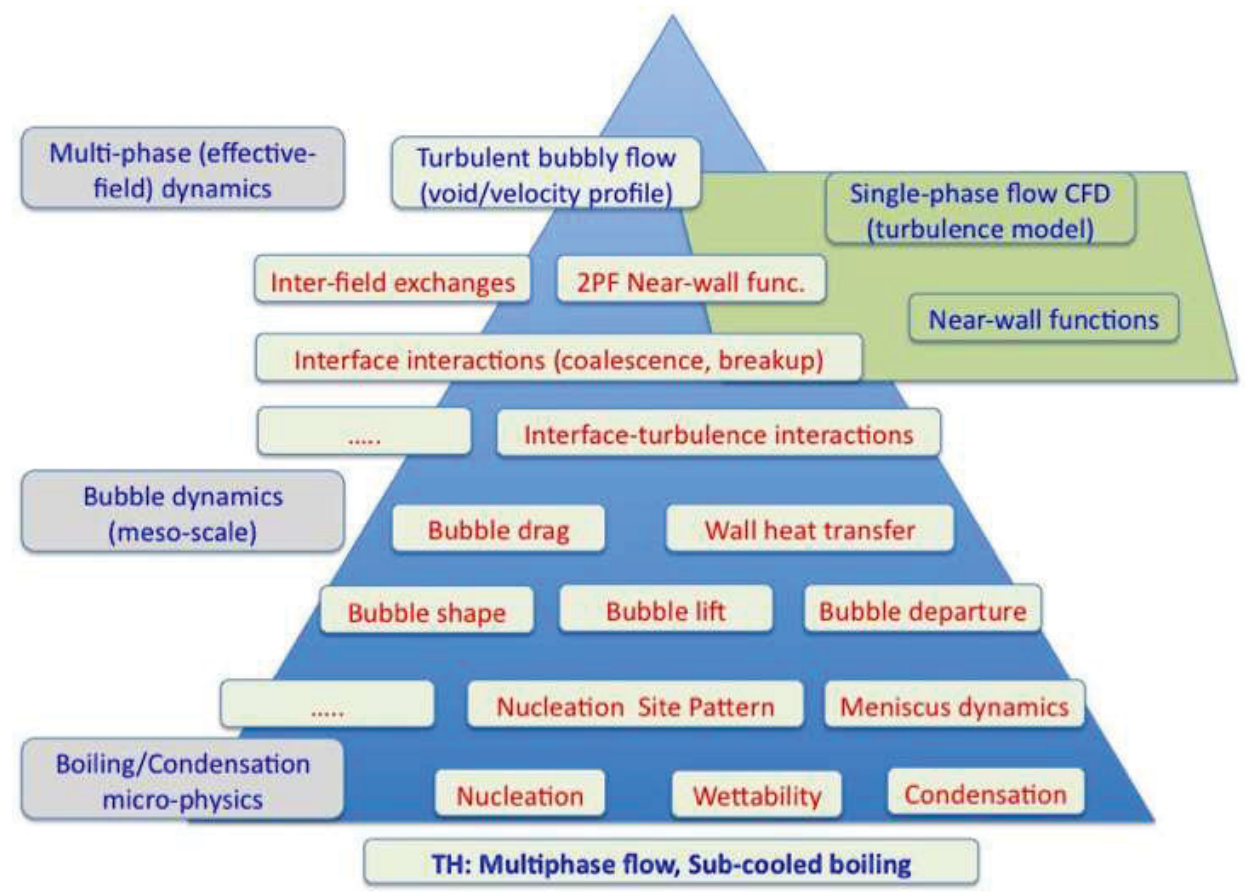

Figure 1.3. The pyramid of the subcooled boiling flow physics and scales [1]. 
Model calibration approach based on modern data assimilation and Bayesian inference techniques offers several advantages, in particular, the capabilities to [5]

- Simultaneously calibrate several control parameters of several closure models;

- Handle multiple heterogeneous dataset at once;

- Account for data quality (relevancy, scalability, and uncertainty);

- Quantify prediction uncertainty;

- Incrementally improve the model with more data.

However, the application of this approach to complex multiscale, multiphysics model calibration/validation is still relatively limited due to the following reasons, among the others: (i) the presence of multiple physical sub-models and their complex couplings, leading to complex correlations between parameters and variables; (ii) high level of model complexity and extensive computational resource requirement, necessitating the construction of a less computationally extensive surrogate/emulator suitable for statistical model analysis; (iii) multi-dimensional and multivariate model predictions, which complicate the construction of a model surrogate/emulator and necessitate a technique for dimensionality reduction; (iv) heterogeneity (in quality and availability) of validation data.

This report presents a case study of complex multiscale, multiphysics model calibration and validation based on data assimilation and Bayesian inference. A realistic model of subcooled flow boiling, commonly employed in many nuclear reactor thermal hydrodynamic and system analysis codes, is used as a target of this calibration/validation exercise. The case study's technical approach includes the following steps [1]:

i. Review modeling approaches and simulation capability for subcooled flow boiling (SFB) at all relevant scales;

ii. Evaluate sub-cooled flow boiling models and their hierarchical decomposition for modeling and validation consistency.

iii. Assess the causes of prediction uncertainty;

iv. Review experimental data and empirical/semi-empirical closure correlations relevant to SFB. Assess the quality of data as well as the applicability of closure correlations;

v. Develop and apply a framework (including infrastructure) for SFB model calibration and validation.

vi. Document the results of the SFB model calibration and validation, lessons learned, and recommendations for improvements.

The work is to be performed in close collaboration with THM, MPO, and AMA experts, and with the CASL Data Center initiative.

\section{OVERVIEW OF SUBCOOLED FLOW BOILING MODELING - CONSERVATION LAWS-BASED AND CLOSURE MODELS}

CASL Advanced Modeling \& Simulation (AMS) capabilities include thermalhydrodynamic models and codes (e.g. COBRA-TF, Hydra-TH) capable of detailing multiphase flows with condensation and boiling in complex geometries of nuclear power reactors. In fact, key CASL challenge problems, such as CIPS (CRUD-Induced Power Shift), DNB (Departure from Nuclear Boiling), etc., involves subcooled flow boiling modeling, 
which is commonly based on the Eulerian-Eulerian (or continuum-continuum) approach to multiphase flow modeling.

Similar to the modeling of other multiphysics problems, modeling of subcooled flow boiling is based on a range of modeling methods. At the macroscopic level, the phenomenology of two-phase transports is normally described using the multiphase continuum formulation with all phases (i.e. both continuous and dispersed) assumed to be interpenetrating continua collocating in space. Such a description of multiphase flows can be mathematically formulated using averaging techniques and the laws of mass, momentum, and energy conservations. The system of conservation equations for each phase (flow field) can therefore be derived, which forms the backbone of the popular Eulerian-Eulerian approach to modeling of multiphase flows. The system of conservation equations needs to be solved numerically, commonly using the finited-difference or finite-element methods which employs time- and geometry-discretization. The convergence and accuracy of the solution depend not only on the used numerical techniques, but also on the temporal and spatial resolutions, which, in many cases, can not capture the fast dynamics and/or small scales of many relevant physical processes.

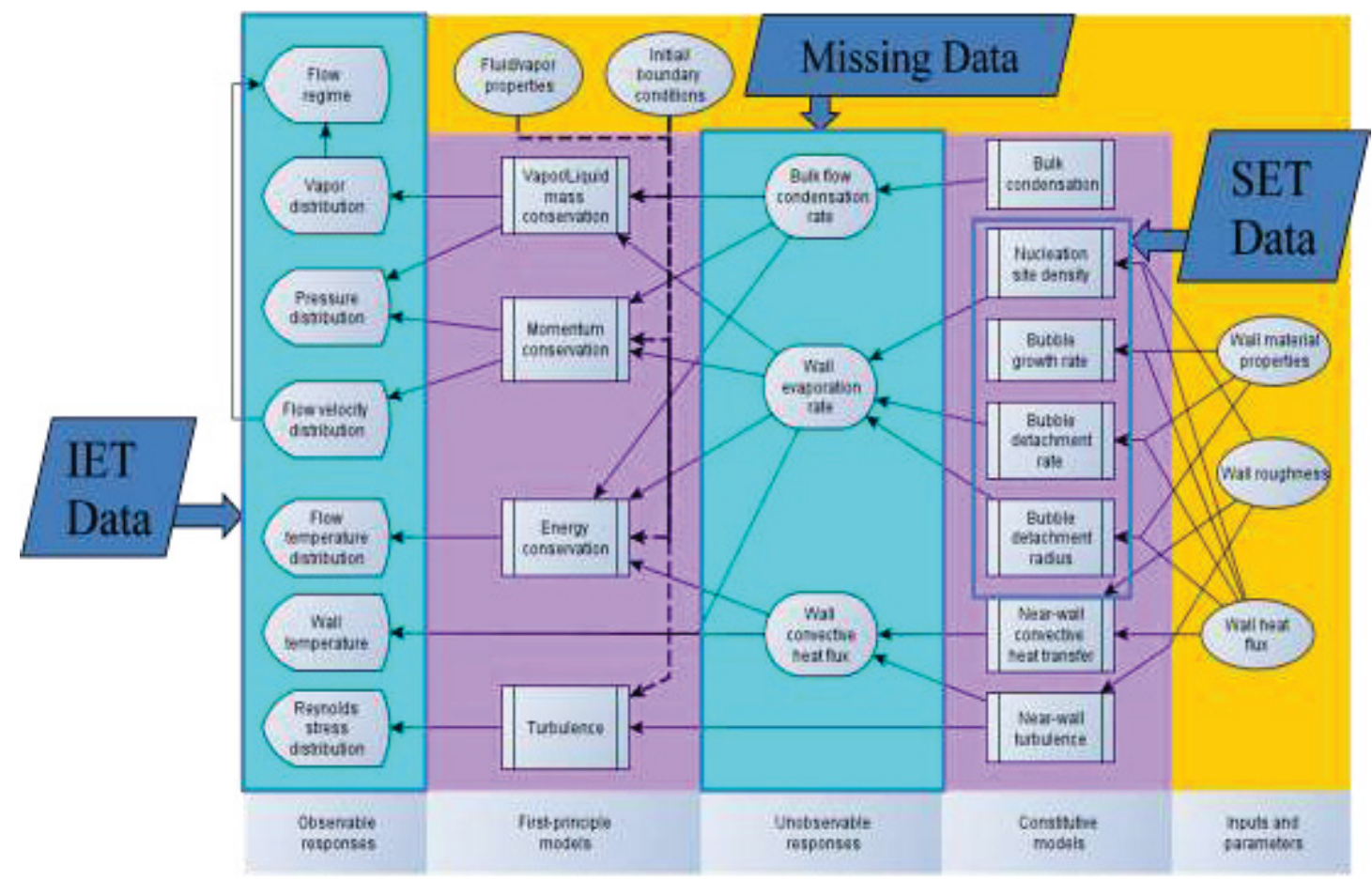

Figure 2.2. Hierarchy of subcooled boiling flow model and validation data [1].

As mentioned earlier, the system of conservation-laws based equations can not cover every aspects of the multiscale, multiphysics subcooled flow boiling phenomenon. As shown in Figure 2.1, many physical interactions are happening at the meso- and micro-scales which include: (i) momentum and heat-mass exchanges between phases (at the phase interfaces), e.g. drag, lift, virtual mass forces; bubble deformation, coalescence, and breakup; bubble condensation, (ii) mechanical and thermal interactions on the heating wall, e.g. nucleation, bubble growth and departure, evaporation and wall heat transfer affected by it. Due to the much difference between these physics and average flow in space and time scales and the deficiency/lack of knowledge/understanding about them, the effects of such small-scale physics on the average flow are normally approximated using the so-called closure models, 
which are commonly derived from separate-effect-test (SET) data. The development and application of empirical/semi-empirical closure models and correlations can be seen as a data assimilation/integration process, which is an essential part of the modeling. Uncertainty in modeling of subcooled flow boiling mostly arises from the necessary use of these datadependent closure models, which are normally the targets of the whole model calibration/validation exercise.

\subsection{Conservation Laws-Based Models of Two-Phase Flow}

The Eulerian-Eulerian multi-fluid model of multiphase flow in the conservative form is based on the following conservation equations [6]:

Mass conservation equation:

$$
\frac{\partial\left(\alpha_{k} \rho_{k}\right)}{\partial t}+\nabla \cdot\left(\alpha_{k} \rho_{k} \vec{u}_{k}\right)=\Gamma_{k}
$$

Momentum conservation equation:

$$
\begin{aligned}
& \frac{\partial\left(\alpha_{k} \rho_{k} \vec{u}_{k}\right)}{\partial t}+\nabla \cdot\left(\alpha_{k} \rho_{k} \vec{u}_{k} \vec{u}_{k}\right)=-\nabla\left(\alpha_{k} p\right)+\nabla \cdot\left[\alpha_{k}\left(\tau_{k}+\tau_{k}^{T}\right)\right]+\alpha_{k} \rho_{k} \overrightarrow{\mathrm{g}} \\
&+\left(\vec{u}_{k i} \Gamma_{k}+p \nabla \alpha_{k}+\vec{M}_{i k}-\nabla \alpha_{k} \cdot \tau_{k}\right)
\end{aligned}
$$

Thermal energy (enthalpy) conservation equation:

$$
\begin{gathered}
\frac{\partial\left(\alpha_{k} \rho_{k} h_{k}\right)}{\partial t}+\nabla \cdot\left(\alpha_{k} \rho_{k} h_{k} \vec{u}_{k}\right)=\nabla \cdot\left[\alpha_{k}\left(\vec{q}_{k}+\vec{q}_{k}^{T}\right)\right]+\alpha_{k} \frac{D_{k} p}{D t} \\
+\left(h_{k i} \Gamma_{k}+q_{k i}^{\prime \prime} a_{i}\right) .
\end{gathered}
$$

The above conservation equations contain various terms which represent mechanical and thermal interactions and mass exchange between phases, e.g. interfacial forces $M_{i k}$, interfacial heat flux $q "{ }_{k i}$ and phase change rate $\Gamma_{k}$. These terms are specified by constitutive closure-laws models, which are to be delineated in the next section.

It is worth noting that the above conservation equations are relatively simpler than the ones proposed by Ishii and Habiki [6] with the phase and interfacial pressures assumed to be equal and some terms omitted. This assumption is significant as it leads to the loss of hyperbolicity and ill-posedness of the whole equation system, which complicate its numerical solution. The causes and some remedies for this problem can be found in the study by Dinh et al. [7].

Different equation forms can be obtained based on the number of fluids and/or fields employed and the assumptions about their interdependence. For instance, in NPHASE model [8] and others [9] [10] [11], multiple fields were employed to describe different morphologies of fluid and gas phases. Some interdependence between continuous and dispersed phase velocities could be also introduced, leading to the simplified drift-flux model [6] [12]. The equation forms can be very different in their hyperbolicity and well-posedness characteristics, which are keys to the robust numerical treatment of the multiphase flow model.

The choice of model equation form also concerns the choice of model dimensionality $(1 \mathrm{D} / 2 \mathrm{D} / 3 \mathrm{D})$ and temporal/spatial resolutions, which can be succinctly termed as model fidelity. Model fidelity determines the "scale" of physics which can be resolved by the model form and the discretization technique. The sub-scale physics which can not be resolved by 
the model equations are described by many constitutive/closure laws. As noted in [2] there should be an agreement between model dimensionality/fidelity choice and validation data requirements.

Many recent advancements in subcooled flow boiling modeling with CFD methods have been resulted from the efforts to improve: (i) two-phase turbulence model; (ii) models of interfacial morphology (bubble size) variation and concentration; and (iii) closure models describing interfacial and flow-wall heat-mass transfers.

Modeling of two-phase flow turbulence mostly focuses on the continuous phase turbulence which is commonly based on a kind of Reynolds-Averaged Navier-Stokes (RANS) transport equations. A $k-\varepsilon$ turbulence model for two-phase flows can be derived [13] [14] with the transport equations for the turbulent kinetic energy, $k$, and the dissipation rate of that energy, $\varepsilon$, given by

$$
\begin{gathered}
\frac{\partial\left(\alpha_{c} \rho_{c} k\right)}{\partial t}+\nabla \cdot\left(\alpha_{c} \rho_{c} \vec{u}_{c} k\right)=\nabla \cdot\left[\alpha_{c}\left(\mu_{c}+\frac{\mu_{t}}{\sigma_{k}}\right)\right]+\alpha_{c} P-\alpha_{c} \rho_{c} \varepsilon \\
\frac{\partial\left(\alpha_{c} \rho_{c} \varepsilon\right)}{\partial t}+\nabla \cdot\left(\alpha_{c} \rho_{c} \vec{u}_{c} \varepsilon\right)=\nabla \cdot\left[\alpha_{c}\left(\mu_{c}+\frac{\mu_{t}}{\sigma_{\varepsilon}}\right)\right]+\frac{\alpha_{c} \varepsilon}{k}\left(C_{\varepsilon 1} P-C_{\varepsilon 1} \rho_{c} \varepsilon\right)
\end{gathered}
$$

where $P$ is the production rate of turbulent kinetic energy.

Compared to the equivalent $k-\varepsilon$ turbulence model for single phase flows, the presence of dispersed phase and interfacial interactions may promote or suppress the turbulence in the carrier phase depending on interfacial morphology and scale.

The turbulent viscosity of the carrier phase which includes the effect of bubble motion (Sato \& Sekoguchi [15]) is defined as

$$
\mu_{t}=C_{\mu} \frac{k^{2}}{\varepsilon}+0.6 D_{b} \alpha_{b}\left|\vec{u}_{r}\right|
$$

where $D_{b}$ is the Sauter-mean bubble diameter and $u_{r}$ is the relative velocity between phases.

The effect of carrier phase's turbulence on the dispersed phase's transport is quantified by the turbulent dispersion force term [6] [16].

In determining interfacial interactions (forces and heat-mass fluxes at interface), information about interfacial morphology and area concentration is needed, which, however, can not be derived from the distribution of a phase volume fraction alone. In thermalhydraulic system analysis codes such as RELAP5, TRACE, CATHARE, etc., a flow regime map is used to identify the flow pattern transition (Figure 2.3), which together with phase volume fraction can help to determine the dominant interfacial topology/geometry/area and suitable set of closure models for interfacial interactions. It is worth noting that the flow regime map is itself a closure model, which will be discussed more in the following section.

Methods to the more "mechanistic" determination of interfacial characteristics have also been proposed which include:

- Bubble number transport model - Riznic \& Ishii [17], Guido-Lavalle et al. [18];

- Interfacial area transport model - Ishii et al. [19] [6], Yao \& Morel [20];

- MUSIG (MUltiple-SIze-Group) population balance model -Yeoh et al. [21] [22], Rzehak \& Krepper [23]; 
- S- $\gamma$ bubble size distribution model - Yun et al. [24] [25].

In the interfacial area transport model, a transport equation for interfacial area of bubbles of similar shape and transport characteristics can be obtained as [6] [26]

$$
\frac{\partial a_{i}}{\partial t}+\nabla \cdot\left(a_{i} \vec{u}_{b}\right)=\frac{2}{3}\left(\frac{a_{i}}{\alpha_{b}}\right)\left[\frac{\partial \alpha_{i}}{\partial t}+\nabla \cdot\left(\alpha_{i} \vec{u}_{b}\right)\right]+\left(\phi_{R C}+\phi_{W E}+\phi_{T I}\right)
$$

with the last three terms designating bubble coalescence due to random collision and wake entrainment, and bubble breakup due to turbulent impact, respectively.

It is noticeable from the above example that an additional model for local interfacial characteristics determination involves more physics/interactions, e.g. bubble breakup and coalescence mechanisms, and requires additional closure models to describe them, which may add uncertainty to the prediction results and further complicate the model and its calibration/validation. Nevertheless, it appears that more precise determination of local interfacial characteristics, in particular, in-flow bubble size, can significantly improve predictions of subcooled boiling flows [25].

\subsection{Closure Laws for Modeling of Subcooled Flow Boiling}

The model of subcooled flow boiling detailed in the previous section requires many closure/constitutive submodels to cover the sub-scale physics, interactions, and transitions (see Figure 1.2), which include:

- Momentum transfer - drag force and non-drag forces (lift, virtual mass, wall lubrication, turbulent dispersion)

- Mechanical interaction of carrier-phase turbulence and dispersed phase

- Interfacial transformation - (bubble) breakup and coalescence

- Heat-mass transfer in the flow - bubble condensation in subcooled bulk flow

- Heat-mass transfer near heating wall - convective heat transfer, nucleation, bubble growth, departure, lift and sliding

- Flow pattern transition (Figure 2.3).

A two-phase flow may acquire different interfacial morphologies and flow patterns (or regimes) (Figure 2.3), which are characterized by very different mechanistic and thermal interactions between phases. In modeling of two-phase flow, empirical flow regime maps are employed to identify local flow pattern/regime based on a common set of coordinates, e.g. superficial phase velocities, local void fraction, etc. This identification of flow regime is then used to switch between different sets of closure models/relations. The use of empirical flow regime maps in two-phase flow modeling has several shortcomings [27] and constitutes a significant source of uncertainty in the modeling [2]. 

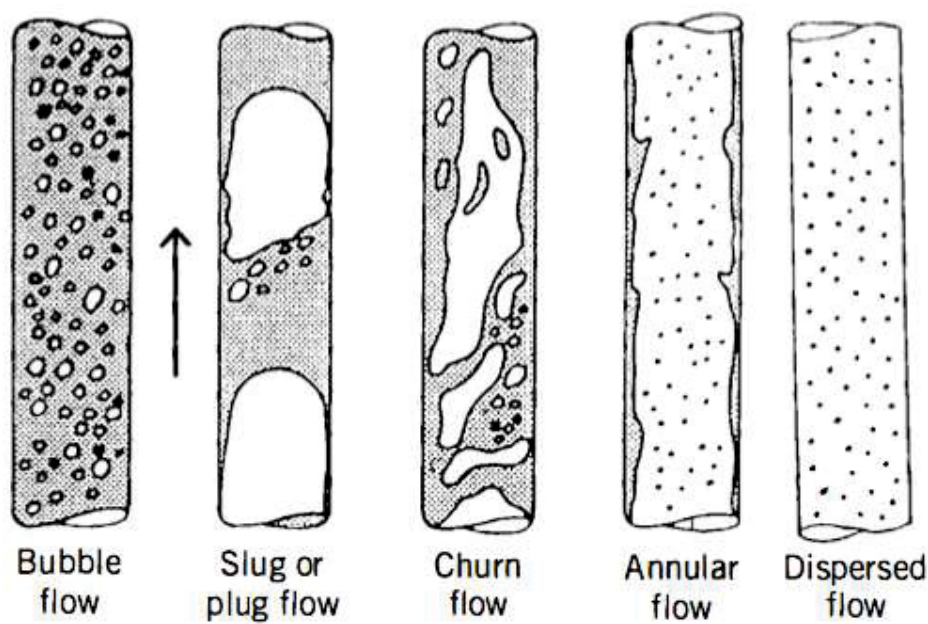

Figure 2.3. Interfacial morphologies and flow patterns in vertical two-phase flows [28].

Simplified 1D two-phase flow models employed in nuclear thermal hydraulic system codes such as RELAP5 and TRACE need closure relations for flow pattern transition, drag force, interfacial heat transfer, and wall heat flux partition [29]. In these models, the boiling heat transfer coefficient is normally determined with empirical/semi-empirical correlations, many of them were surveyed by Guglielmini et al. [30] and Agafonova et al. [31].

More physics and interactions are considered in multidimensional (CFD) modeling of two-phase flow with subcooled boiling. In addition to drag force, various non-drag forces and flow turbulence have to be accounted for. Detailed descriptions and formulations of interfacial forces can be found in [6]. It is notable that the inclusion of interfacial forces may have a profound effect on the mathematical characteristic of a two-fluid model and the stability and convergence of its numerical solution. Some formulation of the virtual mass force, for instance, was found to mitigate the non-hyperbolicity problem which is inherent to a typical six equation two-fluid model of two-phase flow [32] [33].

In multidimensional (CFD) modeling of two-phase flow with subcooled boiling, wall heat transfer and evaporation are key issues, which are usually modeled in a more "mechanistic" manner [34] [35] [36] [37]. The mechanisms of heat transfer from heating wall to flow involving boiling are complex (see an overview by Shekriladze [38]), but generally considered to be: single-phase turbulent convection, surface quenching, and evaporation (Kurul \& Podowski [34]), which are defined as follows

$$
\begin{gathered}
q_{c}=A_{1 f} h_{c}\left(T_{w}-T_{f}\right) \\
q_{q}=A_{2 f} h_{q}\left(T_{w}-T_{f}\right) \\
q_{e}=N_{a} f_{d}\left(\frac{\pi D_{d}^{3}}{6}\right) \rho_{g} h_{f g}
\end{gathered}
$$

where $N_{a}$ designates the active nucleation site density, $D_{d}$ and $f_{d}$ indicate the bubble departure diameter and frequency, respectively, and $A_{1 f}$ and $A_{2 f}$ are the fractions of the areas subjected to convective and quenching heat transfers. The following correlations for $A_{l f}$ and $A_{2 f}$ are hold: 


$$
\begin{gathered}
A_{1 f}+A_{2 f}=1 \\
A_{2 f}=K N_{a}\left(\frac{\pi D_{d}^{2}}{4}\right)
\end{gathered}
$$

with $K$ being a bubble influence factor.

Models have been developed for determination of nucleation site density and bubble departure diameter/frequency, which are shown in Tables 2.1-2.3.

Nucleation site density has been found to be a function of the nucleating cavity radius, $R_{c}$, (or diameter, $D_{c}$ ) which, in turn, is related to wall superheat, $\Delta T_{w}$, and pressure as follows [39]:

$$
R_{c}=\frac{2 \sigma\left(1+\rho_{g} / \rho_{f}\right) / p}{\exp \left[h_{f g} \Delta T_{w} /\left(R T_{w} T_{s}\right)\right]} \approx \frac{2 \sigma T_{s}}{\rho_{g} h_{f g} \Delta T_{w}} .
$$

However, the dependency of nucleation site density on wall superheat is seen to differ significantly from model to model: the exponent in the power function dependencies can vary from 1.805 (Lemmer \& Chawla, 1977) to 6.0 (Wang \& Dhir, 1993).

Nucleation site density is also found to be dependent on the surface wettability, defined by the contact angle $\theta$, as well as the half of cavity cone angle, $\beta$. The effects of these characteristics, however, are only quantified in few latest models.

It is worth mention that many commercial CFD software, such as CFX-4/5, Star-CD/Star$\mathrm{CCM}+$, etc., still employ the relatively simple Lemmert \& Chawla formulation in boiling

\begin{tabular}{|c|c|c|}
\hline Author(s) & Model & Flow conditions \\
\hline $\begin{array}{l}\text { Mikic \& Rohsenow } \\
\text { (1969) }\end{array}$ & $N_{a}=\left(\frac{D_{c, \max }}{D_{c}}\right)^{m}, D_{c}=\frac{4 \sigma T_{s}}{\rho_{g} h_{f g} \Delta T_{w}}$ & $\begin{array}{l}\text { pool boiling, } \\
p \sim 1-13.7 \text { bar }\end{array}$ \\
\hline $\begin{array}{l}\text { Lemmer \& Chawla } \\
\text { (1977) }\end{array}$ & $N_{a}=\left(210 \Delta T_{w}\right)^{1.805}$ & \\
\hline $\begin{array}{l}\text { Kocamustafaogullari } \\
\text { \& Ishii (1983) }\end{array}$ & $\begin{array}{l}N_{a} D_{d}^{2}=f\left(\rho^{*}\right)\left(D_{c} / D_{d}\right)^{-4.4} \propto \Delta T_{w}^{4.4} \\
\rho^{*}=\Delta \rho / \rho_{g}, \Delta \rho=\rho_{f}-\rho_{g}\end{array}$ & $\begin{array}{l}\text { pool boiling, } \\
p \sim 1-198 \text { bar }\end{array}$ \\
\hline Yang \& Kim (1988) & $N_{a}=\bar{N}_{a} \phi(\beta) \exp \left(-\lambda R_{c}\right)$ & \\
\hline Wang \& Dhir (1993) & $N_{a}=7.81 \times 10^{-29}(1-\cos \theta) R_{c}^{-6.0} \propto \Delta T_{w}^{6.0}$ & $\begin{array}{l}\text { pool boiling, } \\
p \sim 1 \text { bar }\end{array}$ \\
\hline $\begin{array}{l}\text { Basu, Warrier and } \\
\text { Dhir (2002) }\end{array}$ & $N_{a}= \begin{cases}3.4 \times 10^{3}(1-\cos \theta) \Delta T_{w}^{2.0} & \Delta T_{w}<15 K \\
0.34(1-\cos \theta) \Delta T_{w}^{5.3} & \Delta T_{w} \geq 15 K\end{cases}$ & $\begin{array}{l}\text { convective } \\
\text { boiling, low } p\end{array}$ \\
\hline Hibiki \& Ishii (2003) & $\begin{array}{l}N_{a}=\bar{N}_{a}\left\{1-\exp \left(-\frac{\theta^{2}}{8 \theta_{*}^{2}}\right)\right\}\left[\exp \left(\frac{\lambda^{\prime} g\left(\rho^{+}\right)}{R_{C}}\right)-1\right] \\
\rho^{+}=\log \left(\rho^{*}\right), \theta_{*}=0.722 \mathrm{rad}, \lambda^{\prime}=2.5 \times 10^{-6} \mathrm{~m}\end{array}$ & $\begin{array}{l}\text { pool \& convec- } \\
\text { tive boiling, } \\
p \sim 1-198 \text { bar }\end{array}$ \\
\hline
\end{tabular}
modeling.

Table 2.1. Some models of active nucleation site density in the literature

Bubble departure frequency is related to bubble waiting time, $t_{w}$, and bubble growth time, $t_{g}$, as follows: 


$$
f_{d}=\frac{1}{t_{w}+t_{g}} .
$$

Models of bubble departure frequency or related parameters are shown in Table 2.2. Bubble departure frequency is seen to be strongly correlated with bubble departure diameter in all models. Cole's formulation is most commonly used in the commercial CFD boiling models.

Table 2.2. Some models of bubble departure frequency in the literature

\begin{tabular}{|c|c|c|}
\hline Author(s) & Model & Flow conditions \\
\hline Jacob \& Friz (1931) & $f_{d} D_{d}=0.078$ & Pool boiling \\
\hline $\begin{array}{l}\text { Peebles \& Garber } \\
(1953)\end{array}$ & $f_{d} D_{d}=1.18\left(\frac{t_{g}}{t_{g}+t_{w}}\right)\left(\frac{\sigma g \Delta \rho}{\rho_{f}^{2}}\right)^{1 / 4}$ & Pool boiling \\
\hline Zuber (1959) & $f_{d} D_{d}=0.59\left(\frac{\sigma g \Delta \rho}{\rho_{f}^{2}}\right)^{1 / 4}$ & Pool boiling \\
\hline Cole (1960) & $f_{d}=\sqrt{\frac{4 g \Delta \rho}{3 D_{d} \rho_{f}}}$ & $\begin{array}{l}\text { Pool boiling - Hydrodynamic } \\
\text { region (dominated by drag and } \\
\text { buoyancy forces) }-\rho_{f} \gg \rho_{g}\end{array}$ \\
\hline Ivey (1967) & $f_{d}=0.9 \sqrt{g / D_{d}}$ & $\begin{array}{l}\text { Pool boiling - Hydrodynamic } \\
\text { region }\end{array}$ \\
\hline Ivey (1967) & $f_{d}=$ const $/ D_{d}^{2}$ & $\begin{array}{l}\text { Pool boiling - Thermodynamic } \\
\text { region }\end{array}$ \\
\hline $\begin{array}{l}\text { Basu, Warrier, and } \\
\text { Dhir (2005) }\end{array}$ & $\begin{aligned} t_{w} & =139.1\left(\Delta T_{w}^{-4.1}\right) \\
t_{g} & =\frac{D_{d}^{2}}{45 a_{f} \mathrm{Ja}_{\text {sup }} \exp \left(-0.02 \mathrm{Ja}_{s u b}\right)}\end{aligned}$ & $\begin{array}{l}\text { Convective boiling on flat plate } \\
\text { heater }\end{array}$ \\
\hline
\end{tabular}

A summary of some commonly used models of bubble departure diameter is presented in Table 2.3. The models are seen to be very different in the scope of flow characteristics which were considered. For instance, only models by Tolubinsky \& Konstanchuk, Unal, Basu et al. and Situ et al. took into account the effect of fluid subcooling. The effect of wettability (contact angle) was considered in the models by Friz, Kocalmustafaogullari [40], Basu et al. [41], and "mechanistic" models by Klausner et al. [42] and Situ et al. [43]. Model by Kutateladze \& Gogonin [44] took into consideration the effect of wall superheat.

Experimental study by Surgue [45] indicated the dependence of bubble growth and departure in subcooled flow boiling on a range of thermal and flow characteristics, namely, heat flux, flow rate, subcooling, pressure and surface inclination angle. The bubble departure diameter was found to increase with increasing heat flux and decreasing flow rate, subcooling, pressure and surface inclination angle.

The mechanistic models (by Klausner et al. [42], Situ et al. [43], Yun et al. [24], etc.) are most complex and do not have closed-form solutions, but were found to be able to provide reasonably better predictions of the above-observed trends. However, significant difference between experimental data and model predictions was still found [45], even for the latest Yun et al.'s model. 
A majority of commercial CFD boiling models, however, still employ relatively simple models by Tolubinsky \& Konstanchuk, Unal or Kocamustafaogullari.

Table 2.3. Some models of bubble departure diameter in the literature

\begin{tabular}{|c|c|c|}
\hline Author(s) & Model & Flow conditions \\
\hline Friz (1935) & $D_{d F}=0.208 \theta l_{c}, \quad l_{c}=\sqrt{\frac{\sigma}{g \Delta \rho}}$ & low $p$ \\
\hline $\begin{array}{l}\text { Cole \& Rosenhow } \\
\text { (1968) }\end{array}$ & $D_{d}=1.5 \times 10^{-4} \sqrt{\frac{\sigma}{g \Delta \rho}}\left(\frac{\rho_{f} C_{p f} T_{s}}{\rho_{g} h_{f g}}\right)^{5 / 4}$ & \\
\hline $\begin{array}{l}\text { Tolubinsky \& } \\
\text { Konstanchuk (1970) }\end{array}$ & $D_{d}=\min \left[0.0006 \exp \left(-\Delta T_{s u b} / 45\right), 0.0014\right]$ & \\
\hline Unal (1976) & $\begin{array}{l}D_{d}=\frac{2.42 \times 10^{-5} p^{0.709} A}{\sqrt{B \Phi}}, A=\frac{\Delta T_{s a t} k_{f} \gamma}{2 \rho_{g} h_{f g} \sqrt{\pi a_{f}}}, B=\frac{\Delta T_{s u b}}{2\left(1-\rho_{g} / \rho_{f}\right)} \\
\gamma=\sqrt{\frac{k_{w} \rho_{w} C_{p w}}{k_{f} \rho_{f} C_{p f}}}, \Phi=\max \left[1,\left(\frac{u_{f}}{0.61}\right)^{0.47}\right]\end{array}$ & $\begin{array}{l}p \sim 1-177 \text { bar } \\
\Delta T_{\text {sub }}=3-86 \mathrm{~K}\end{array}$ \\
\hline $\begin{array}{l}\text { Kutateladze \& } \\
\text { Gogonin (1979) }\end{array}$ & $\begin{array}{l}D_{d}=\left[0.25\left(1+10^{5} K_{1}\right)^{1 / 2}\right] l_{c} \\
K_{1}=\left(\frac{\rho_{f} C_{p f} \Delta T_{w}}{\rho_{g} h_{f g} \operatorname{Pr}_{f}}\right)^{2}\left(\frac{\mu_{f}^{2}}{\rho_{f} \sigma l_{c}}\right)\end{array}$ & $\begin{array}{l}\text { Convective } \\
\text { boiling of } \\
\text { saturated liquids }\end{array}$ \\
\hline $\begin{array}{l}\text { Kocamustafaogullari } \\
\text { (1983) }\end{array}$ & $D_{d}=1.27 \times 10^{-3}\left(\frac{\Delta \rho}{\rho_{g}}\right)^{0.9} D_{d F}$ & $p \sim 1-142$ bar \\
\hline $\begin{array}{l}\text { Basu, Warrier, and } \\
\text { Dhir (2005) }\end{array}$ & $\begin{aligned} D_{d}=1.3(\sin \theta)^{0.4} l_{c}\left[0.13 \exp \left(1.75 \mathrm{E}-4 \mathrm{Re}_{l}\right)\right. \\
+0.05] \mathrm{Ja}_{\text {sup }}^{0.45} \exp \left(-0.0065 \mathrm{Ja}_{\text {sup }}\right)\end{aligned}$ & $\begin{array}{l}\text { Convective } \\
\text { boiling on flat } \\
\text { plate heater }\end{array}$ \\
\hline $\begin{array}{l}\text { Klausner, Mei, } \\
\text { Bernhard, Zeng } \\
\text { (1993) }\end{array}$ & $\begin{array}{l}\text { Mechanistic model of bubble departure/lift-off based } \\
\text { on detailed force balance analysis [42] }\end{array}$ & $\begin{array}{l}\text { Saturated forced } \\
\text { convective } \\
\text { boiling }\end{array}$ \\
\hline $\begin{array}{l}\text { Situ, Hibiki, Ishii, } \\
\text { Mori (2005) }\end{array}$ & $\begin{array}{l}\text { Mechanistic model of bubble departure/lift-off based } \\
\text { on detailed force balance analysis [43] }\end{array}$ & $\begin{array}{l}\text { Subcooled boiling } \\
\text { flow }\end{array}$ \\
\hline
\end{tabular}




\subsection{Sensitivity of boiling model predictions to closure model parameters and model parameter calibration issues}

Sensitivity tests [46] [47] conducted with the Star-CD boiling model, which employs (i) Lemmert \& Chawla's formulation of nucleation site density; (ii) Cole's formulation of bubble departure frequency; and (iii) Tolubinsky \& Konstanchuk's formulation of bubble departure diameter (written in a more general form as $D_{d}=d_{0} \exp \left(-\Delta T_{\text {sub }} / \Delta T_{\text {ref }}\right)$ ), indicated:

- Small effect of quenching heat flux on model predictions of pressure drop, average wall temperature and void fraction;

- Dominance of wall evaporation in two-phase flows with boiling;

- Strongest effect of bubble departure diameter, in particular, the bubble size scaling parameter, $d_{0}$, on evaporative heat transfer model.

Strong effect of the bubble departure diameter model and related parameters on boiling model prediction can be explained by the strong relationship between evaporation rate and bubble departure diameter (i.e. proportional to $D_{d}^{3}$ ).

In the experimental study by Surgue [45], a number of factors in addition to flow subcooling, $\Delta T_{s u b}$, were found to affect bubble departure diameter which include pressure, mass flow rate, surface orientation, etc. These dependencies, however, are not accounted for in the simple Tolubinsky \& Konstanchuk's correlation, which leaded to a need to calibrate parameters $d_{0}$ and $\Delta T_{\text {ref }}$ as showed in the work by Krepper and Rzehak [48] [23]. These parameters were seen to be calibrated down with the increase of mass flow rate and wall heat flux (with pressure unchanged) [23]. To match the tests of Bartolomej \& Chanturiya, parameters $d_{0}$ and $\Delta T_{\text {ref }}$ had to be adjusted to $0.6 \mathrm{~mm}$ and $45 \mathrm{~K}$, respectively.

The work by Krepper and Rzehak also demonstrated a rudimentary "calibration" of the Lemmert \& Chawla's formulation of nucleation site density which is given in a more general form as

$$
N_{a}=\bar{N}_{a}\left(\frac{\Delta T_{w}}{\Delta T_{\text {refN }}}\right)^{p} .
$$

It was found in [48] that best results were obtained with $\bar{N}_{a}=0.8 \times 10^{6} \mathrm{~m}^{-2}$ and $\Delta T_{\text {ref } N}=10$ $\mathrm{K}$ for Bartolomej and Chanturiya's tests.

Given the importance of bubble departure and nucleation models in defining wall evaporation and overall flow void fraction, these models were selected for calibration in this study.

Since both bubble departure diameter and nucleation site density determine the wall evaporation rate, "non-identifiability" issue arises if insufficient data are available for their separate calibrations. The so-called "multiple response" calibration of these models is a possible way to overcome this problem [49]. 


\section{CALIBRATION AND VALIDATION OF SUBCOOLED FLOW BOILING MODEL}

As noted in [2], advanced modeling of multiphysics problems, in general, and subcooled flow boiling, in particular, involves a lot of uncertainty related to:

- inadequacy of equation form. Although model equation form is based on the relatively more universal conservation laws and represented using mathematically rigorous ensemble-averaged PDEs, the averaging method, the chosen number of representative fields, the assumptions used in derivation of field equations (regarding field pressure, interfacial morphology and geometry, phase separation, etc.) would determine the equation form adequacy. This depends also on the specifics of the considered problem, i.e. whether it involves flow regime change, crisis of heat transfer, critical flow conditions, etc.

- incorrect/improper application of closure laws. A range of small-scale physics can not be directly modeled due to the lack of physical understanding or the limitation of computational resolution/method, and are represented by various closure laws (or models). They are empirically or semi-empirically based and, therefore, much less universal and scalable compared to the conservation laws-based models. Extensive calibration of those models is required whenever they are applied to different problems with different conditions;

- limitation of numerical methods and computational resources in solving extremely large systems of non-linear and differently coupled model equations;

- uncertainty in specifying initial and boundary conditions of complex physical systems which vary greatly from scenario to scenario.

Model calibration, validation, and uncertainty quantification (CVUQ) are therefore indispensable both in the development and improvement of complex multiphysics models and in the determination of accuracy and usefulness of the predictions of practical problems with the models.

\subsection{An Overview of Calibration, Validation, and Uncertainty Quantification (CVUQ) of CASL Advanced Modeling \& Simulation Capabilities}

The Advanced Modeling \& Simulation (AMS) capabilities being developed under CASL are characterized by high fidelity, high (temporal/spatial) resolution, and high levels of coupling of physics and scales. As pointed out by Dinh [1], the calibration and validation of such capabilities require a new CVUQ approach, which is different from the "commonsense" physics-by-physics, scale-by-scale calibration/validation. Moreover, an analysis of validation data available for the CASL CIPS challenge problem indicated a need for a comprehensive validation data strategy/plan (VDP) to support the new CASL CVUQ strategy and activities [3] [1].

As described in [50], the so-called "common-sense" physics-by-physics, scale-by-scale approach to multiphysics model calibration and validation, schematically shown in Figure 3.1 (left panel), suffers from several shortcomings, e.g.

- incapability to account for data quality and uncertainty; 
- inability to quantify prediction uncertainty;

- ambiguity in determination of the reasons of "wrong" model predictions;

- difficulty with using IET data for calibration/validation of large number of closure models - non-identifiability problem;

- difficulty in calibration/validation of physics and scale coupling models due to the lack of relevant data;

- not allowing incremental model update based on newly available data.

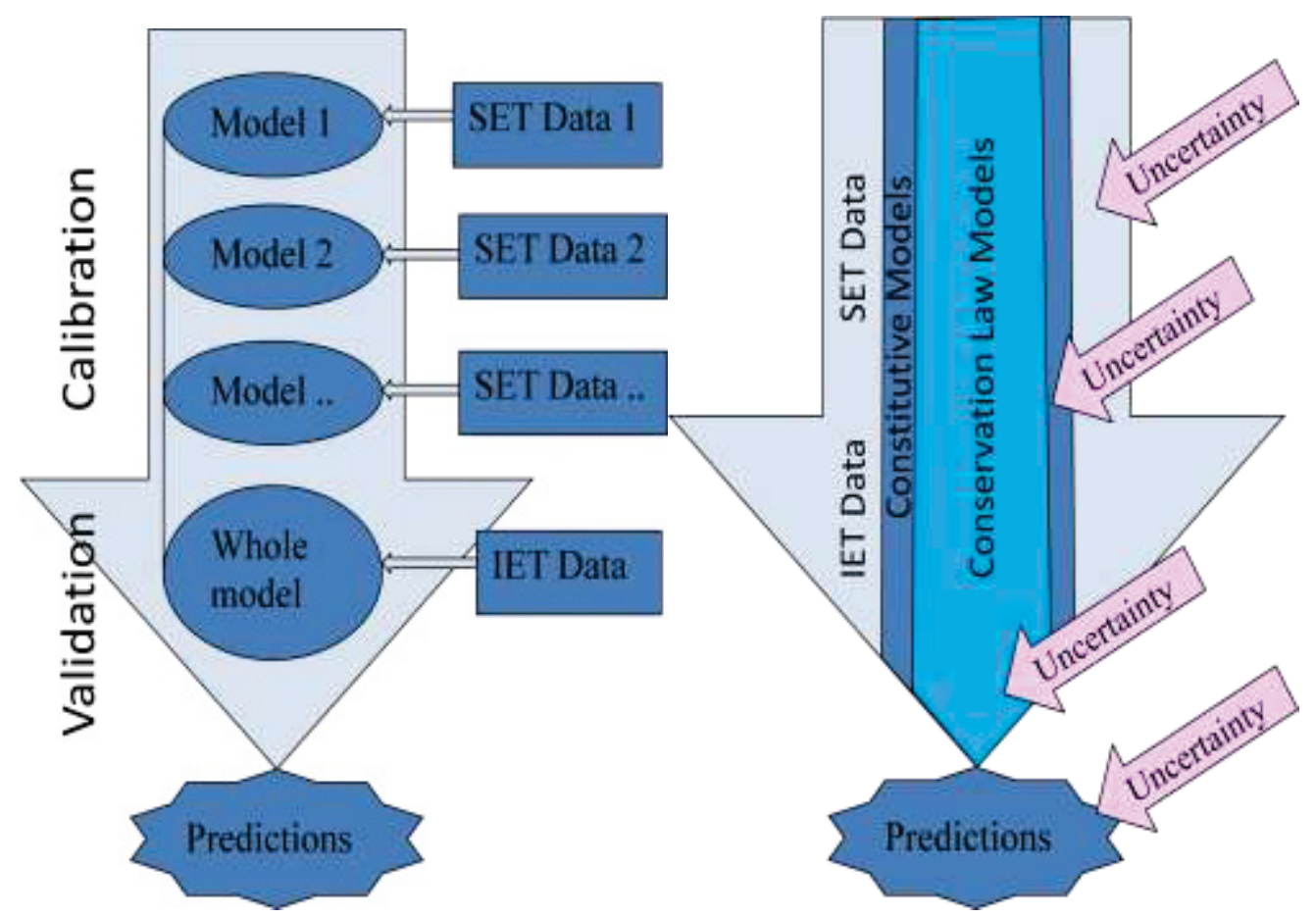

Figure 3.1. "Common-sense" approach to multiphysics model calibration \& validation (left) versus "total data-model integration" approach (right) [50].

CASL has been increasingly employing more advanced CVUQ techniques which utilizes different statistical methods and tools, e.g. DAKOTA, GPMSA, MCMC, DRAM/DREAM, etc., to assess model sensitivity and prediction uncertainty and to better the efficient use of available data of different qualities in CVUQ process.

"Total data-model integration" approach based on Bayesian inference and data assimilation techniques has been proposed in [1] and [50] for complex multiphysics model calibration, validation, and uncertainty quantification (Figure 3.1 (right panel)), which is potentially able to:

- account for uncertainty in observed data or take into consideration the "weight" or "values" of data given their uncertainty;

- quantify prediction uncertainty;

- exploit the results of past validations/calibrations (in construction of more informative priors for analysis), i.e. sequential model updating;

- handle "missing" data and allow the validation of unobserved quantity predictions;

- handle multiple (multiphysics) coupled models using Bayesian influence networks.

Technical implementation of the proposed "total data-model integration" approach is difficult as it requires a combining of multiple heterogeneous data streams and dealing with 
multidimensional multivariate model inputs/outputs. A preliminary realization of the approach was delineated in [50] and [51], which employs a range of statistical modeling methods and techniques, e.g. surrogate model construction using a process convolution technique based Principal Component Analysis (PCA) and Gaussian processes (GPs), and Bayesian calibration using Markov chain Monte Carlo (MCMC) sampling. Calibration of the case-study 1D SFB model described in [50] and [51] was successfully conducted with use of two one-dimensional (1D) datasets (one for void fraction and one for fluid temperature). It is noteworthy that, in this case study, not only the closure model parameters have been calibrated, but also the model discrepancy, which indicates the adequacy of overall model form, has been evaluated.

The proposed calibration, validation, and uncertainty quantification approach, while offering some flexibility in data usage (i.e. allowing the use of data of different origins, types, qualities, etc.), does impose additional requirements on data collection, validation and characterization, which were discussed in [1] [2].

\subsection{Validation data support for subcooled flow boiling modeling}

A survey of available data on subcooled flow boiling is given in [2]. The survey not only summarized available sources of data relevant to subcooled flow boiling, but also suggested a strategy to data characterization, i.e. defining the quality and usability of data in calibration and validation of nuclear thermal-hydraulic simulation models and codes. A guideline for collection and characterization of validation data was also proposed, which is applicable to not only subcooled flow boiling, but also other CASL challenge problems. The guideline basically delineated the use of physics-dependent representative dimensionless groups to assess the relevancy and scalability of data, and measurement/data derivation errors to define data uncertainty.

Measurement data on subcooled flow boiling can mostly be classified into either integral effect test (IET) data, i.e. distributions of phase volume fraction, temperature, etc., and separate effect test (SET) data, i.e. measurements and observations of nucleation, bubble dynamics, wall heat flux, $\mathrm{CHF}$, etc. To assess the quality of data, estimates of measurement error as well as error related to indirect derivation of data of interest from measurements are needed [2].

Table 3.1: Estimates of scaling factors of Bartolomej et al.'s [52] [53] and DEBORA [54] experiments compared to the PWR conditions.

\begin{tabular}{|c|c|c|c|}
\hline $\begin{array}{c}\text { Scaling } \\
\text { factor }\end{array}$ & $\begin{array}{c}\text { Bartolomej et } \\
\text { al.'s experiments }\end{array}$ & $\begin{array}{c}\text { DEBORA } \\
\text { experiments }\end{array}$ & $\begin{array}{c}\text { PWR } \\
\text { conditions }\end{array}$ \\
\hline$p / p_{c r}$ & $0.136-0.682$ & $0.353-0.633$ & 0.712 \\
\hline$D_{h} / D_{h, P W R}$ & 1.1 & 1.745 & 1.0 \\
\hline$\rho_{g} / \rho_{f}$ & $0.053 \div 0.161$ & $0.072 \div 0.169$ & 0.176 \\
\hline $\mathrm{We}, 10^{3}$ & $0.151 \div 17.107$ & $0.73 \div 2.18$ & 3.32 \\
\hline $\mathrm{Bo}, 10^{-4}$ & $1.9 \div 13.3$ & $3.23 \div 4.36$ & 3.56 \\
\hline$x_{\text {eq,inlet }}$ & $-(0.455 \div 0.156)$ & $-(0.126 \div 0.059)$ & -0.357 \\
\hline
\end{tabular}


Integral-effect boiling experiments relevant to reactor prototypical conditions, i.e. high pressure, high heat flux, high flow rate, complex geometry, etc., are scarce. Among the others, the experiments by Bartolomej et al.'s [52] [53] and DEBORA experiments [54] are notable for their scaling relatively well with PWR conditions (see Table 3.1). The NUPEC PSBT tests [55], which were conducted on realistic PWR bundle geometries under reactor prototypical conditions (pressure, temperature, heat flux) with water used as working fluid, are also worth mentioning.

Separate effect boiling experiments (SETs) are much more abundant, but have been mostly conducted under small-scale, simple-geometry, laboratorial (controlled) and/or atmospheric/low pressure conditions, to investigate:

- Boiling curve [56] [57];

- Wall heat flux partitioning [41] [58];

- Onset of Nucleate Boiling (ONB) and Significant Void (OSV) [59] [60] [57];

- Departure from Nucleate Boiling (DNB) and Critical boiling Heat Flux (CHF) [57];

- Nucleation site density [61] [39] [60] [62];

- Interfacial area density [63] [57] [64];

- Bubble growth and departure dynamics [65] [63] [66] [62];

- In-flow bubble dynamics [67] [68] [64];

- Boiling crisis - DNB and CHF [69] [70] [71] [72] [73].

The data from SETs have often been used to derive empirical correlations, which are employed as closure models in CMFD codes (see Section 2.2). Due to the empirical origination of closure models, the application of such codes in simulation of nuclear reactor problems is questionable without proper calibration of all closure relationships.

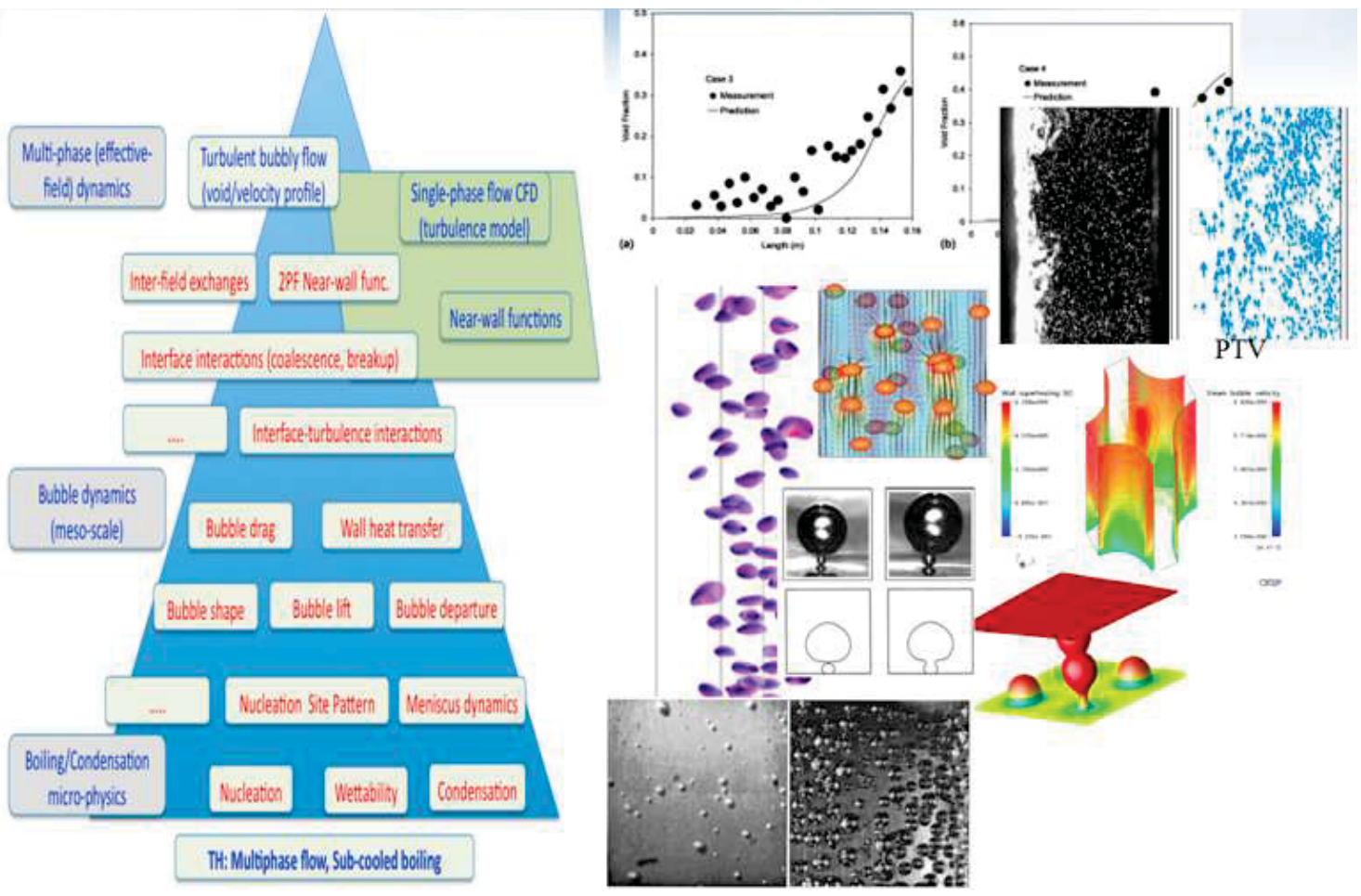

Figure 3.2. Subcooled flow boiling physics and validation data sources (which include measurement and DNS data). 
High-fidelity high-resolution Direct Numerical Simulation (DNS) using advanced firstprinciple thermal-hydrodynamic models and powerful computational resources, e.g. [74] [75], also increasingly become a valuable source of high-quality validation data.

\subsection{Calibration of Subcooled Flow Boiling Model Using Multivariate Heterogeneous Data}

The subcooled flow boiling model considered in this work (details in Section 2) is a relatively simple, but typical multi-scale, multi-physics model, which comprises many closure sub-models that require calibration. Strong couplings between small-scale physics (hence, the closure relationships) and lack of appropriate validation data for many of them would make their separate calibration for reactor applications a difficult task.

The objective of this work was to implement and apply the "total data-model integration" approach described in Section 3.1 to the SFB model calibration. Multivariate heterogeneous data of different scale levels on spatial distributions of void fraction and fluid temperature as well as bubble departure diameter were used in the calibration process.

Only bubbly flow regime was considered in this work. The sub-models describing bubble departure diameter and nucleation site density, which, together, determine the wall evaporation rate, were the subjects of calibration. The relatively simple, but commonly used, Tolubinsky \& Konstanchuk's formulation of bubble departure diameter and Lemmert \& Chawla's formulation of nucleation site density were considered. The parameters selected for calibration include $d_{0}(\mathrm{UncDb}), \Delta T_{r e f}(\mathrm{UncTsub})$, and $\bar{N}_{a}(\mathrm{UncNa})$ (see descriptions in Section 2.3).

Data used in this case study calibration/validation include 1D axial distributions of void fraction and fluid temperature together with measurements of bubble departure diameter.

Experimental data on axial void fraction distribution obtained in Bartolomej et al.'s experiments (Table 3.2) [52], which are scaled relatively well with the PWR conditions, were used in the calibration. The pipe diameter and flow rate for all these data were constant at 24 $\mathrm{mm}$ and $890 \mathrm{~kg} /\left(\mathrm{m}^{2} \mathrm{~s}\right)$, respectively. These data were obtained for upward bubble two-phase flow with forced convection subcooled boiling heat transfer. The error of void fraction measurement was estimated to be less than 0.01 in absolute value [53].

Since there was no measurement of axial fluid temperature distribution in Bartolomej et al.'s experiments, these data were generated from simulations conducted for the conditions listed in Table 3.1.

Table 3.1: Conditions of experimental data by Bartolomej et al.'s [52] used in the calibration.

\begin{tabular}{|c|c|c|c|}
\hline Experiment & $\mathbf{p}, \mathbf{M P a}$ & $\begin{array}{c}\text { Inlet } \\
\mathbf{T}_{\text {sub }}, \mathbf{K}\end{array}$ & $\begin{array}{c}\text { Heat flux, } \\
\mathbf{k W} / \mathbf{m}^{\mathbf{2}}\end{array}$ \\
\hline 1 & 3.0 & 23.9 & 380 \\
\hline 2 & 3.0 & 47.0 & 790 \\
\hline 3 & 4.5 & 26.4 & 380 \\
\hline 4 & 4.5 & 52.4 & 790 \\
\hline
\end{tabular}


Data on bubble departure diameter were also artificially generated based on Tolubinsky \& Konstanchuk's data (Figure 3.3) with some scaling applied to take into account high pressure condition (i.e. smaller bubble departure diameter with higher pressure).

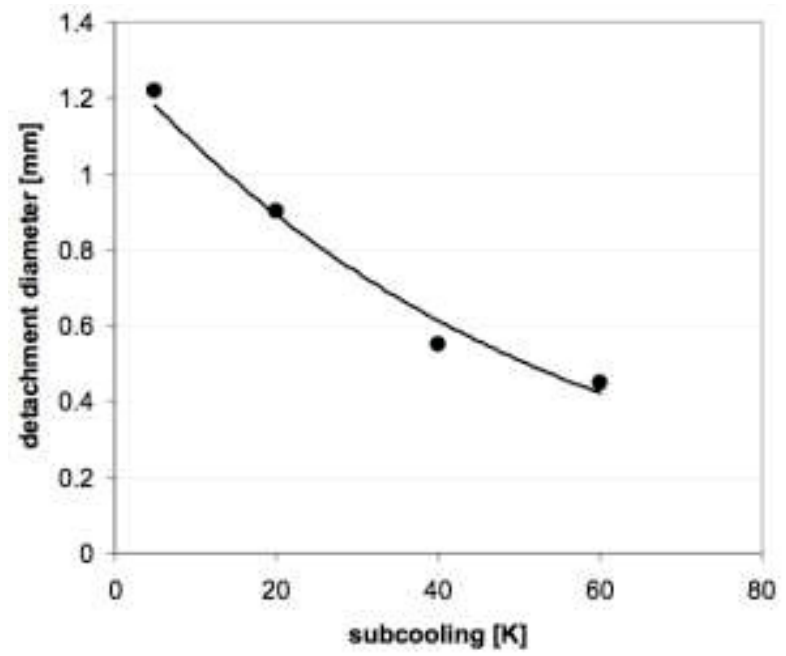

Figure 3.3. Measured bubble departure sizes by Tolubinsky \& Konstanchuk (dots) and the best fit of Tolubinsky \& Konstanchuk's correlation by Krepper \& Rzehak (line) [48].

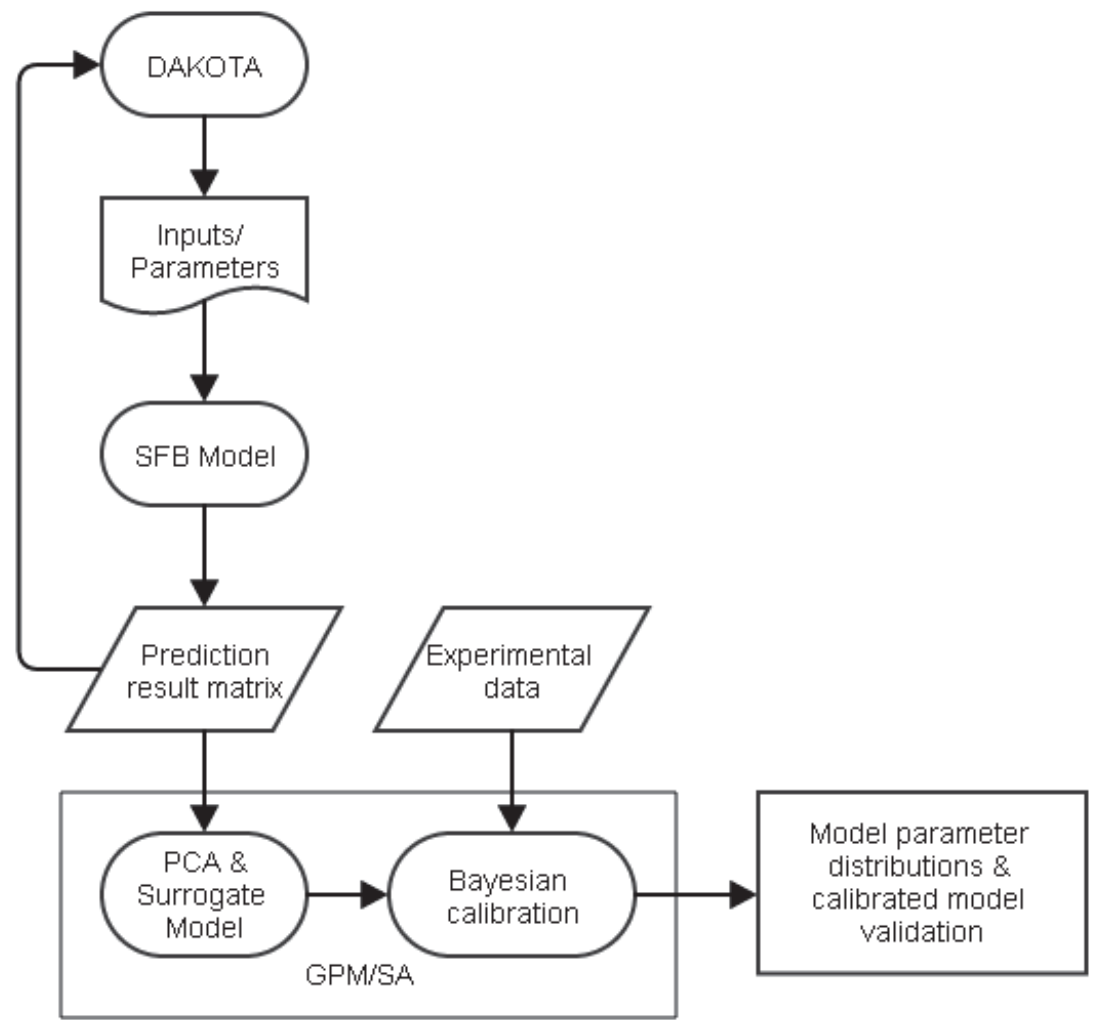

Figure 3.4. The workflow of SFB model calibration and validation. 
Bayesian calibration of reference bubble departure diameter, subcooling temperature, and nucleation site density parameters (see formulations in Section 2.3) was carried out with use of the LANL Gaussian Process Models for Simulation Analysis (GPM/SA) toolbox [76]. The calibration process was conducted in the following steps ${ }^{\text {a }}$ (Figure 3.4):

1. Generating simulation "data" needed for the construction of a model surrogate using the SNL DAKOTA tool [77];

2. Constructing a model surrogate using a combination of Principal Component Analysis (PCA) [78], process convolution technique [79] [80], and Gaussian processes (GPs);

3. Conducting Bayesian calibration using Markov chain Monte Carlo (MCMC) sampling.

300 simulation predictions were generated with the runs controlled by DAKOTA. The inputs and calibration parameters were varied in the ranges shown in Table 3.2. Multidimensional distributions of inputs and calibration parameters were generated by the DAKOTA Latin Hypercube Sampling (LHS) as shown in Figure 3.5.

Table 3.2. Ranges of inputs and calibration parameters.

\begin{tabular}{|c|c|c|c|c|c|c|}
\hline & $\begin{array}{c}\boldsymbol{p}, \\
\mathbf{M P a}\end{array}$ & $\begin{array}{c}\text { Inlet } \\
\boldsymbol{T}_{\text {sub, }}, \\
\mathbf{K}\end{array}$ & $\begin{array}{c}\text { Heat flux, } \\
\boldsymbol{q}_{\text {wall, }}, \\
\mathbf{k W} / \mathbf{m}^{2}\end{array}$ & $\begin{array}{c}\text { Ref. bubble } \\
\text { departure } \\
\text { diam., } \boldsymbol{d}_{\mathbf{0}}, \mathbf{m m}\end{array}$ & $\begin{array}{c}\text { Ref. } \\
\text { subcooling, } \\
\Delta \boldsymbol{T}_{\boldsymbol{s u b} \boldsymbol{b}}, \mathbf{K}\end{array}$ & $\begin{array}{c}\text { Ref. active } \\
\text { nucleation site } \\
\text { density, } \overline{\boldsymbol{N}}_{\boldsymbol{a}}, \mathbf{1} / \mathbf{m}^{\mathbf{2}}\end{array}$ \\
\hline Min & 2 & 20 & 360 & 0.1 & 30 & $1 \times 10^{5}$ \\
\hline Max & 5 & 55 & 800 & 0.8 & 60 & $1 \times 10^{6}$ \\
\hline
\end{tabular}

${ }^{\text {a }}$ Future integration of DAKOTA and GPM/SA will allow all these steps conducted under DAKOTA control. 


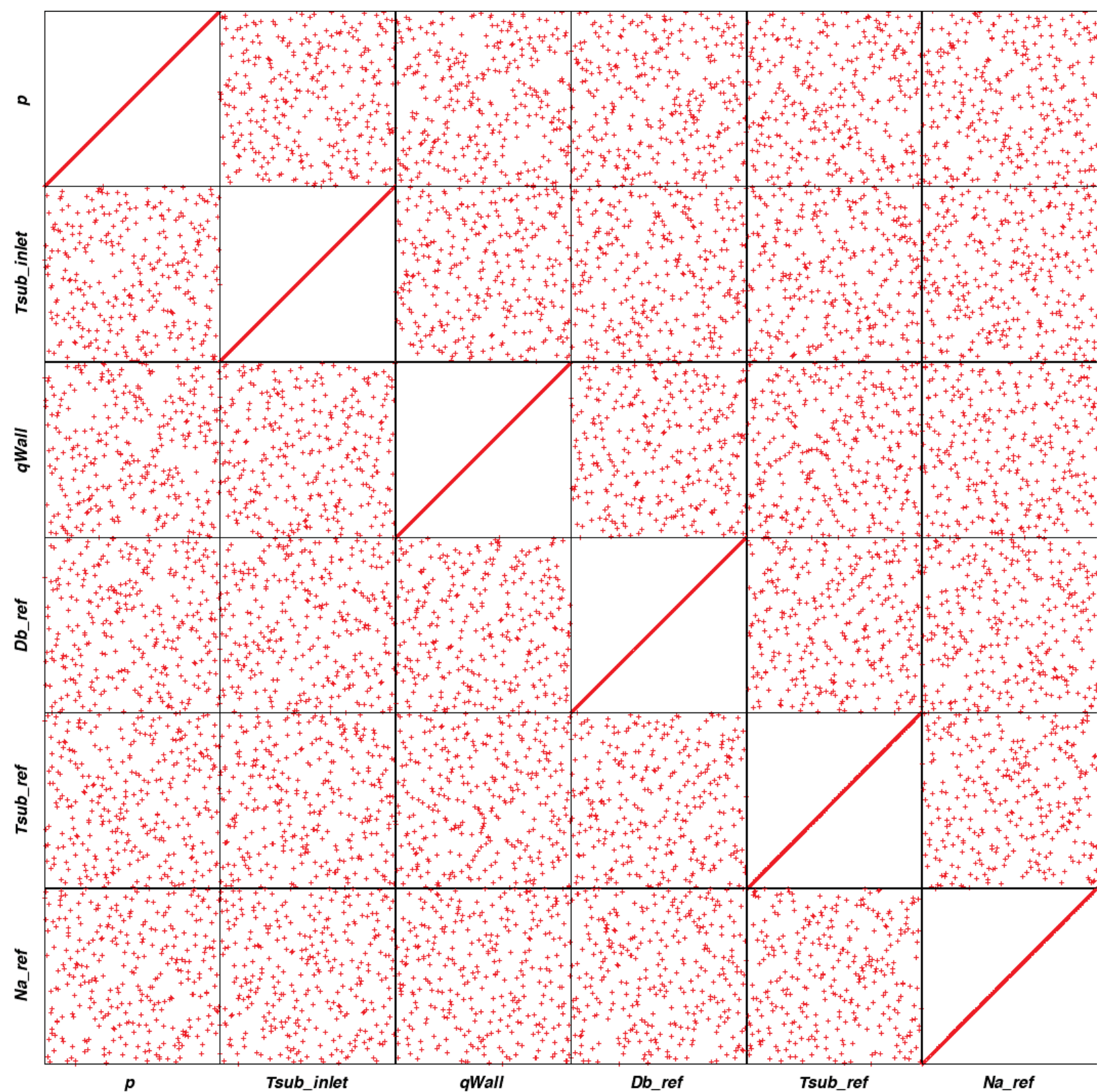

Figure 3.5. The LHS designs of inputs and parameters.

\subsubsection{Construction of a Multivariate Model Surrogate with Gaussian Processes, PCA, and Process Convolution}

The extensive computational resources and times required by modern multiscale multiphysics modeling codes make their direct use in statistical model analysis (where tens of thousands of posterior samplings and associated model evaluations would be needed) impractical. A less computationally-expensive surrogate model (emulator) is usually necessary, which employs various techniques for dimensionality reduction and/or reduced order modeling.

Principal Component Analysis (PCA) [78], which is normally applied to identify patterns in data, can also be used as a dimensionality reduction technique. PCA employs 
a limited set of linearly uncorrelated principal components (whose number is less than or equal the number of original variables) to "explain" a majority of variance in the observations (simulation results). As shown in Figure 3.6, 99.9\% of variance in the 300 predictions of void fraction and fluid temperature distributions can be explained with the first six major principal components.

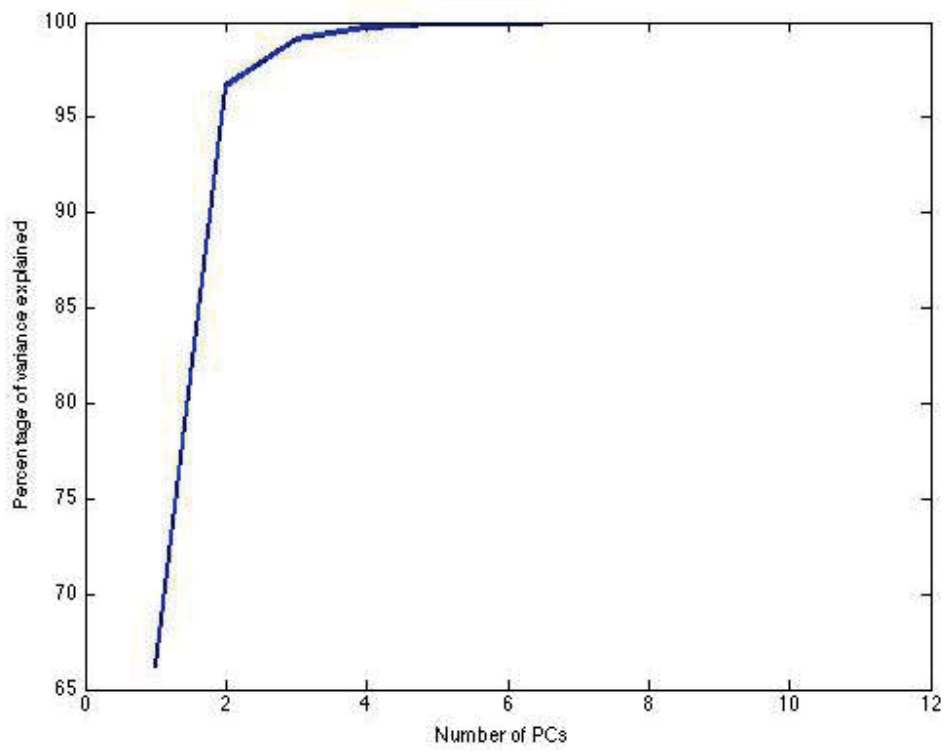

Figure 3.6. Accumulative percentage of variance in joint void fraction and fluid temperature simulation data "explained" by different numbers of principal components.

Relationship between observed data $\boldsymbol{D}$ and model prediction (or response) $\boldsymbol{M}$ can be expressed as [81]

$$
\boldsymbol{D}=\boldsymbol{M}(\boldsymbol{x}, \boldsymbol{\theta})+\delta(\boldsymbol{x})+\epsilon(\boldsymbol{x})
$$

with $\delta(\boldsymbol{x})$ being a model discrepancy/bias function; $\epsilon$ indicating the observation error/uncertainty; $\boldsymbol{x}$ denoting the vector of $n_{x}$ known variable inputs, i.e. pressure, inlet fluid subcooling and wall heat flux in this study; and $\boldsymbol{\theta}$ being the vector of $n_{\theta}$ calibration parameters.

A process convolution technique was employed to build statistical models for emulator $\boldsymbol{M}(\boldsymbol{x}, \boldsymbol{\theta})$ and discrepancy $\delta(\boldsymbol{x})$, which may be high-dimensional and/or highly multivariate [81] [80].

According to [80], multivariate emulator which approximates (high-dimensional) real model response can be constructed as follows

$$
\boldsymbol{M}(\boldsymbol{x}, \boldsymbol{\theta})=\sum_{i=1}^{n_{p c}} \mathbf{k}_{i} \omega_{i}(\boldsymbol{x}, \boldsymbol{\theta})+\boldsymbol{e}
$$

where $\left\{\mathbf{k}_{i}\right\}$ is a collection of orthogonal basis vectors obtained as a result of the PCA, $\omega_{i}(\boldsymbol{x}, \boldsymbol{\theta})$ are the weights defined over input space, $n_{p c}$ is the number of PCs used to capture all significant variances, and $\boldsymbol{e}$ is an error term accounting for the "noise" effect of omitted PCs.

Each weight $\omega_{i}$ is assumed to be a zero-mean Gaussian process and expressed as $\omega_{i}(\boldsymbol{x}, \boldsymbol{\theta}) \sim \mathcal{N}\left[0, c_{\omega i}\left((\boldsymbol{x}, \boldsymbol{\theta}),\left(\boldsymbol{x}^{\prime}, \boldsymbol{\theta}^{\prime}\right)\right)\right]$ where the covariance function $c_{\omega}$ is defined as [80] 


$$
c_{\omega i}\left((\boldsymbol{x}, \boldsymbol{\theta}),\left(\boldsymbol{x}^{\prime}, \boldsymbol{\theta}^{\prime}\right)\right)=\lambda_{\omega i}^{-1} \prod_{l=1}^{n_{x}} \rho_{\omega i, l}^{4\left(\boldsymbol{x}_{\boldsymbol{l}}-\boldsymbol{x}_{l}^{\prime}\right)^{2}} \prod_{k=1}^{n_{\theta}} \rho_{\omega i, k+n_{x}}^{4\left(\boldsymbol{\theta}_{\boldsymbol{k}}-\boldsymbol{\theta}_{k}^{\prime}\right)^{2}}
$$

with the control hyperparameters $\lambda_{\omega i}$ (precision) and $\rho_{\omega i}$ (correlation length) to be defined (together with $\boldsymbol{\theta}$ ) in the calibration process. The collection of weights associated with the simulations have mean zero and variance 1 by construction, motivating our statistical modeling choice of zero-mean Gaussian processes for the weights with independent prior distributions for $\lambda_{\omega i}$ centered at 1 ; we choose Gamma $(5,5)[82]$ having mean 1 and variance 0.2 . The independent prior distributions for $\rho_{\omega i}$ are taken to be $\operatorname{Beta}(1,0.1)$ to emphasize effect sparsity [80].

Both $\delta$ and $\epsilon$ can be assumed to be normally distributed with $\epsilon$ having a zero mean, i.e. $\delta(\boldsymbol{x}) \sim \boldsymbol{N}\left[m_{\delta}(\boldsymbol{x}), c_{\delta}\left(\boldsymbol{x}, \boldsymbol{x}^{\prime}\right)\right]$ and $\epsilon(\boldsymbol{x}) \sim \mathcal{N}\left[0, c_{\epsilon}\left(\boldsymbol{x}, \boldsymbol{x}^{\prime}\right)\right]$ with $m$ and $c$ being the mean and covariance functions, respectively. $\epsilon$ represents measurement error that often has a distribution very close to normal as stated by the Central Limit Theorem [83]. Justification of choosing a Gaussian process to represent prior distribution of unknown function $\delta$ can be found in [5].

In [51], the 1D model bias/discrepancy $\delta(\boldsymbol{x})$ was constructed as a linear combination of 7 normal kernels placed at equidistant locations along the pipe. This resulted in a discrepancy model analogous in form to emulator $\boldsymbol{M}(\boldsymbol{x}, \boldsymbol{\theta})$, having independent zero-mean Gaussian process weights. A preliminary study conducted in this work (using 5 normal kernels) indicated that the discrepancies were in the bounds of the order 0.001 for void fraction and $10^{-6}$ for bubble diameter. Consequently, discrepancy was not considered in the following analysis.

A single set of covariance parameters was assumed to apply across these weight processes, with a diffuse prior distribution for the precision parameter $(\operatorname{Gamma}(1,0.0001)$ having mean and standard deviation 10,000) and identical priors as above for the correlation length parameters. The covariance function for $\epsilon$ was assumed to be $c\left(x, x^{\prime}\right)=\frac{\sigma_{\epsilon}^{2}}{\lambda_{\epsilon}} \boldsymbol{I}(\boldsymbol{x}=$ $\left.\boldsymbol{x}^{\prime}\right)$ where $\boldsymbol{I}\left(\boldsymbol{x}=\boldsymbol{x}^{\prime}\right)$ was the indicator function taking value 1 when $\boldsymbol{x}=\boldsymbol{x}^{\prime}$ and 0 otherwise, $\sigma_{\epsilon}$ was set equal to 0.06 for the void fraction data and 2.0 for the fluid temperature data, respectively, and $\lambda_{\epsilon}$ was assigned a prior distribution of Gamma $(1000,1000)$ having mean 1 and variance 0.001 (effectively assigning fixed residual standard deviation of $\sigma_{\epsilon}$ to each observed response).

\subsubsection{Model Calibration and Validation with GPM/SA}

In the Bayesian calibration step, the posterior probability distributions of the considered parameters are sampled with MCMC. Following the Bayes theorem, the posterior distributions of parameters $\theta$ can be computed as follows:

$$
\pi(\boldsymbol{\theta} \mid \boldsymbol{D}, \boldsymbol{S}) \propto \mathcal{L}(\boldsymbol{D}, \boldsymbol{S} \mid \boldsymbol{\theta}) \pi(\boldsymbol{\theta})
$$

where $\pi(\boldsymbol{\theta})$ is the prior probability distribution of $\boldsymbol{\theta}$ (taken to be uniform on the ranges of Table II) and $\mathcal{L}(\boldsymbol{D}, \boldsymbol{S} \mid \boldsymbol{\theta})$ is the "likelihood" of the observation $\boldsymbol{D}$ and simulation data $\boldsymbol{S}$ (used to construct the emulator) given specific values of $\boldsymbol{\theta}$.

Given the above assumptions about the distributions of data, observation error, and model discrepancy, the 'likelihood' function is also a normal probability density function defined as

$$
\mathcal{L}(\boldsymbol{D}, \boldsymbol{S} \mid \boldsymbol{\theta}) \propto \exp \left[-\frac{1}{2}\left(\boldsymbol{D}^{\mathrm{T}} \boldsymbol{S}^{\mathrm{T}}\right) \boldsymbol{V}^{-1}\left(\boldsymbol{D}^{\mathrm{T}} \boldsymbol{S}^{\mathrm{T}}\right)^{\mathrm{T}}\right]
$$


with $\boldsymbol{V}$ being a matrix which combines the variance and covariance matrices of $\boldsymbol{M}, \delta$ and $\epsilon$ to give the covariance matrix of the collection of observation and simulation data $(D$, S) [5].

With the model (and statistical model) parameters determined by the above posterior realizations, predictions using the calibrated emulator and discrepancy model can be generated at any new inputs (pressure, inlet subcooling, and wall heat flux).

The GPMSA toolbox was set up to enable model calibration with cross-correlated multivariate datasets, i.e. 1D void fraction \& fluid temperature distributions and bubble departure diameter in this study. Cross-covariance was accounted for empirically through PCA on the combined datasets.

\subsubsection{Calibration of SFB Model with Void Fraction and Fluid Temperature Data Only}

In this calibration, only data on one-dimensional (axial) void fraction and fluid temperature distributions (assumed to be correlated) were used. These data can be considered to be of similar type since they describe distributions of variables over a common grid of spatial locations (along the pipe axis).

In the analysis, the void fraction and fluid temperature simulation data sets were separately centered and scaled, then stacked to create a single matrix of simulated output to which PCA was applied. The result of the PCA applied to the combined void fraction and fluid temperature predictions indicated that up to $99.9 \%$ of variance can be captured by the first 6 principal components (PCs). The subsequent analyses utilized 6 PCs (Figure 3.7).
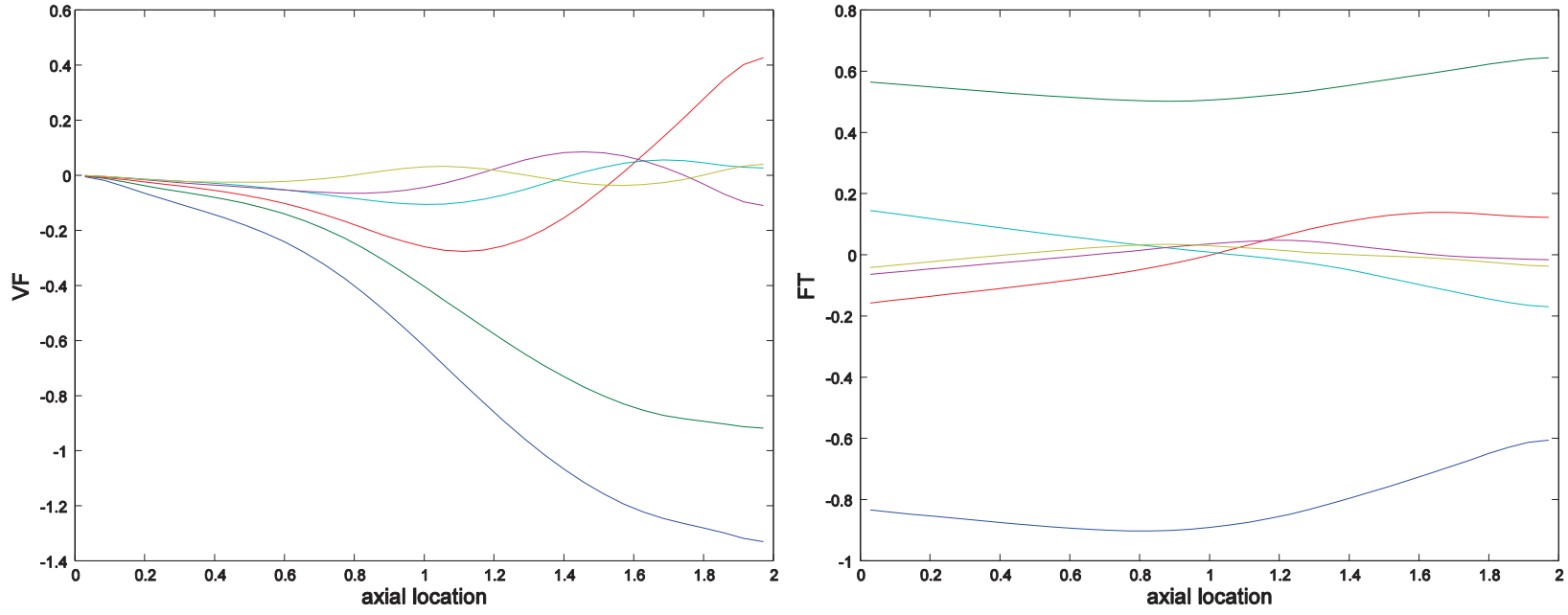

Figure 3.7. Variations of void fraction (left) and fluid temperature (right) captured by six principal components (1-blue; 2-green; 3-red; 4-cyan; 5-purple; 6-brown). 

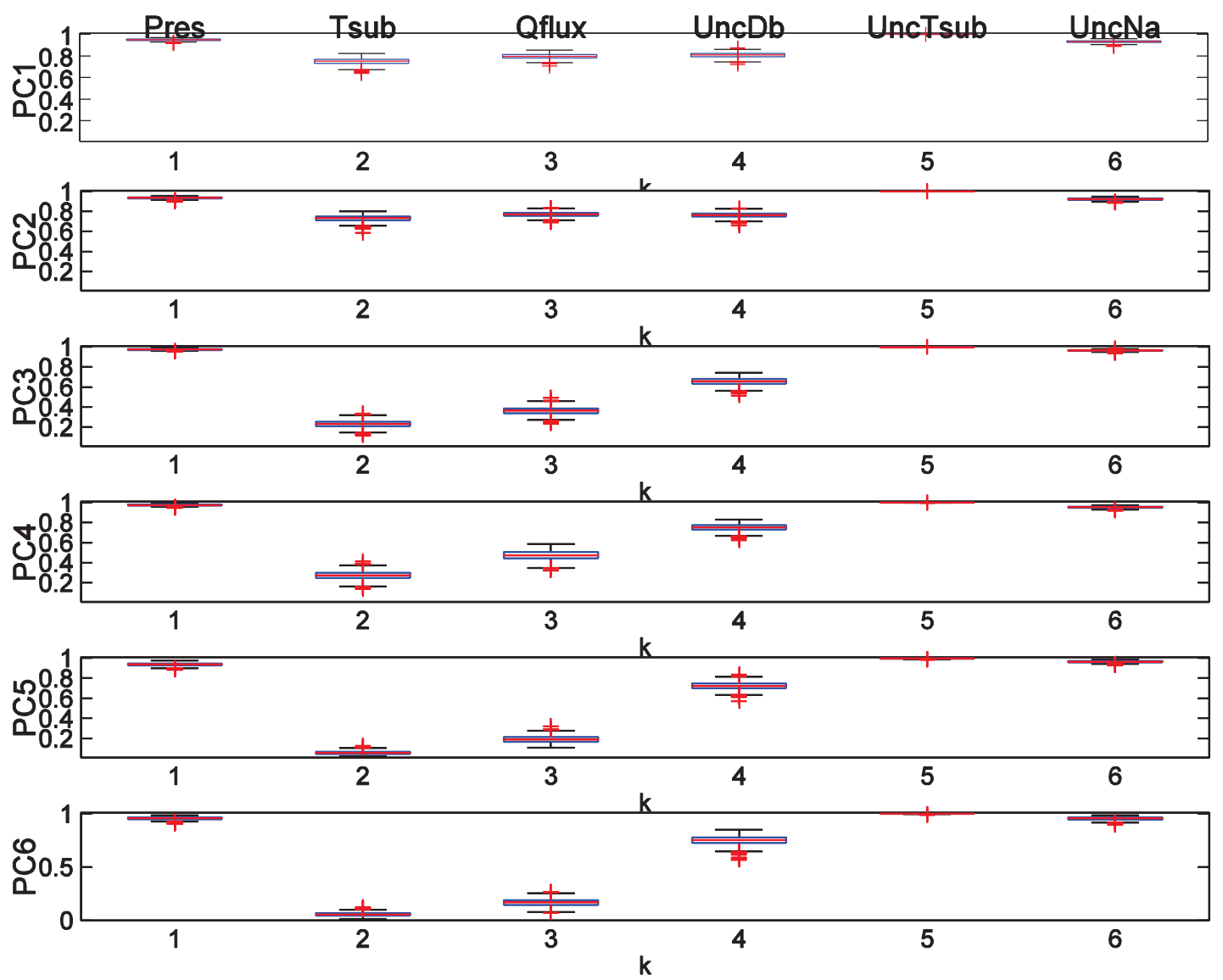

Figure 3.8. Boxplots of the marginal posterior distributions of correlation lengths $\boldsymbol{\rho}_{\boldsymbol{\omega}}$ parameters of the statistical model (emulator) for void fraction and fluid temperature outputs.

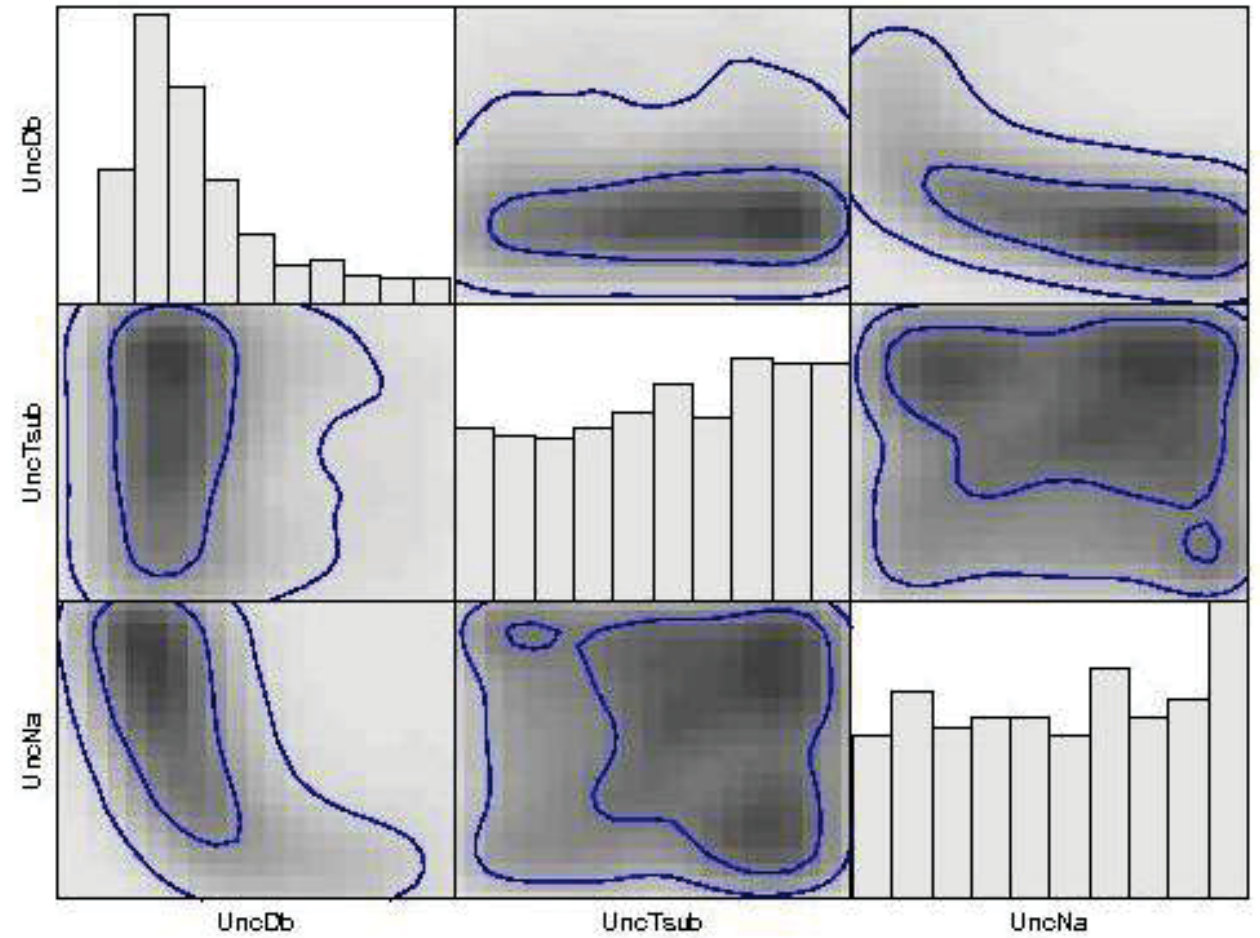

Figure 3.9. Posterior distributions of the calibration parameters. 
With the standard deviations of void fraction and fluid temperature assumed to be 0.06 and $2.0 \mathrm{~K}$, respectively, parameters calibration was conducted as previously described with the results shown in Figures 3.8-3.9. Relative insensitivity of the output to parameter $\Delta T_{r e f}\left(\right.$ UncTsub) is seen in Figure 3.8 (as its $\boldsymbol{\rho}_{\omega i}$ is close to unity), which is also manifested by the wide spread in the maginal posterior distributions for this parameter and its lack of correlation with other parameters (Figure 3.9).
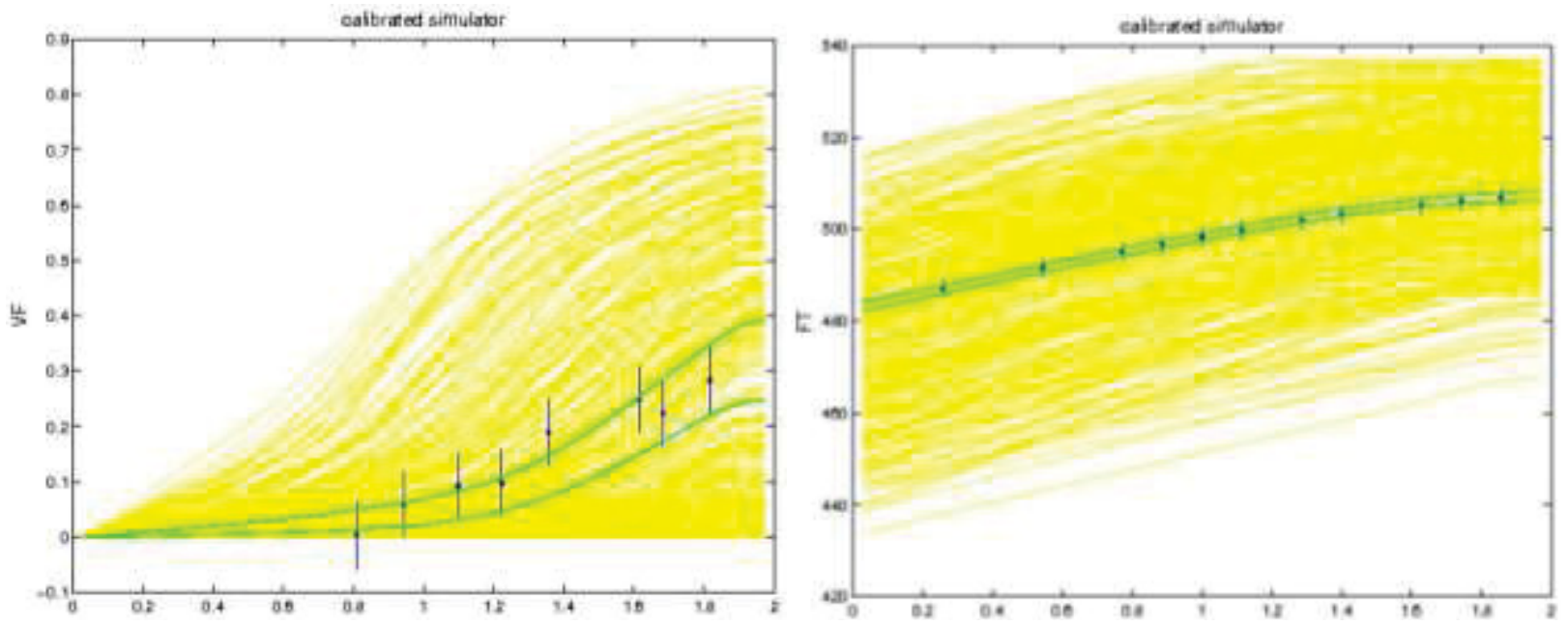

Figure 3.10. Prediction of experiment 1 (Table 3.1) with calibrated model.
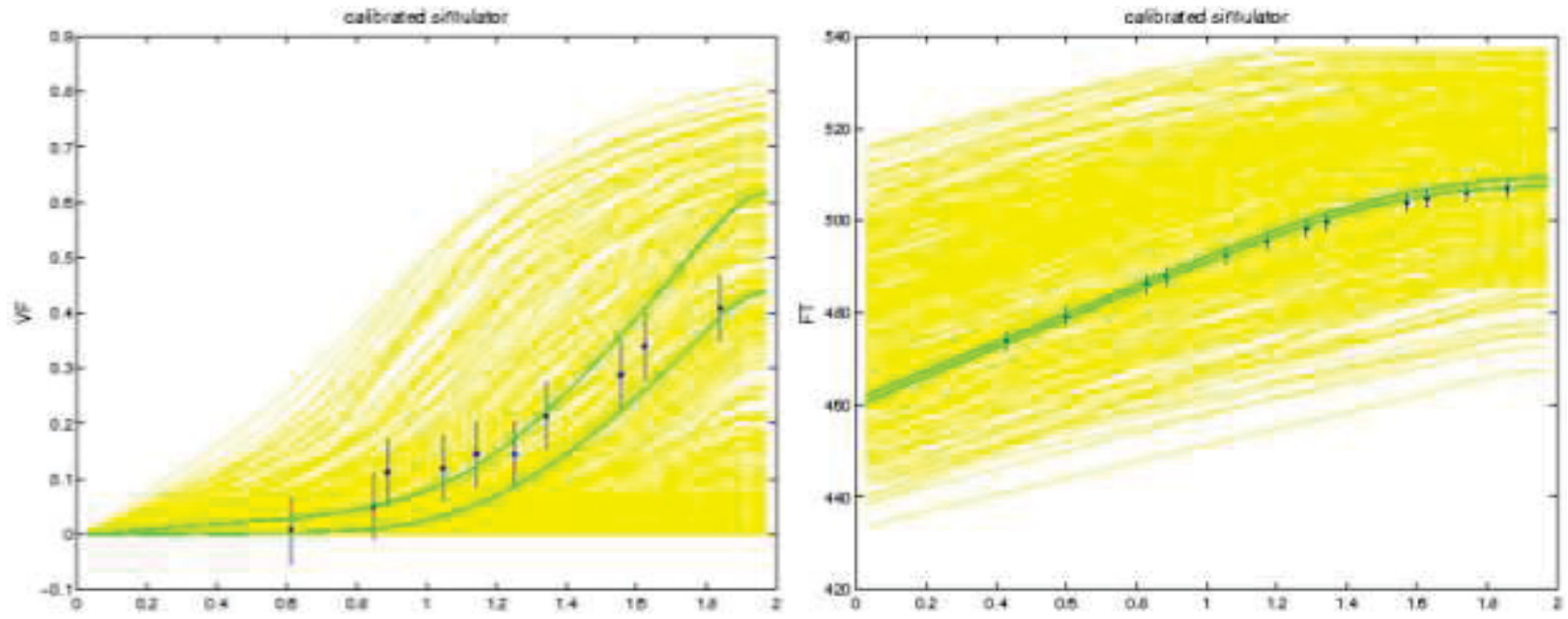

Figure 3.11. Prediction of experiment 2 (Table 3.1) with calibrated model.
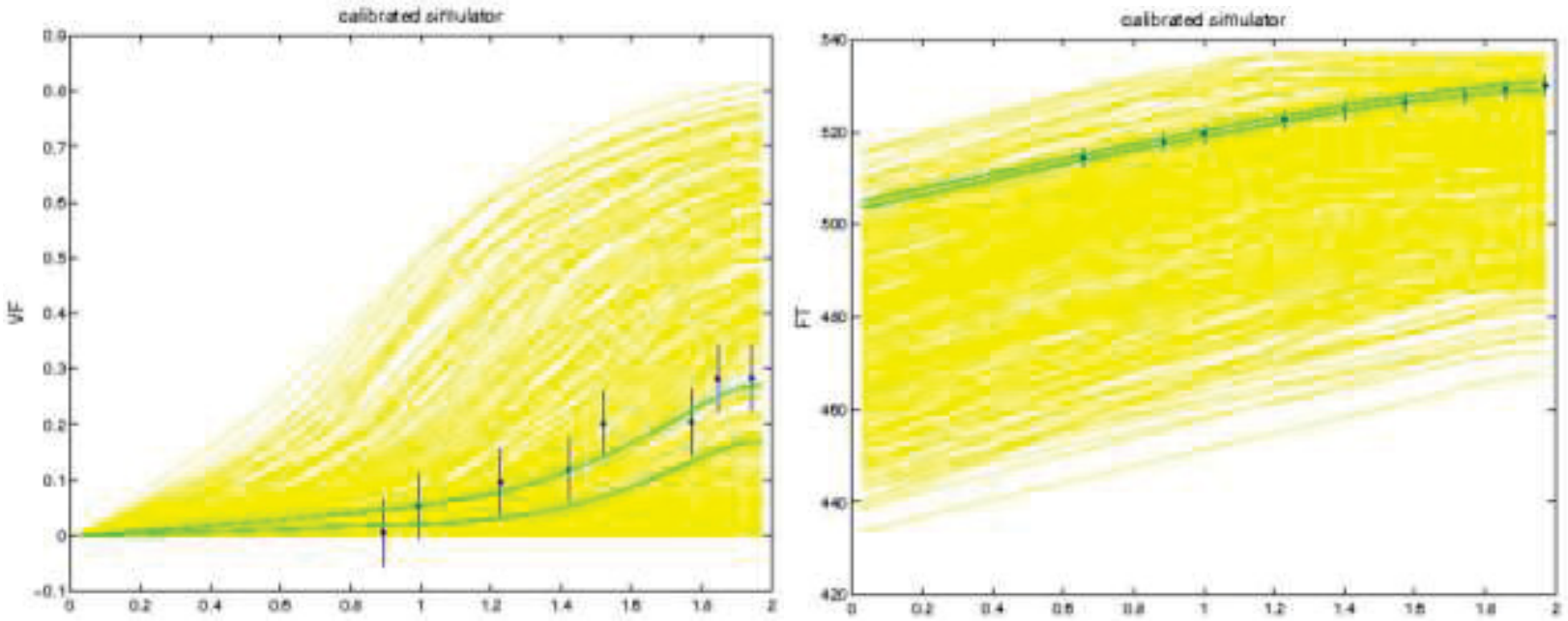


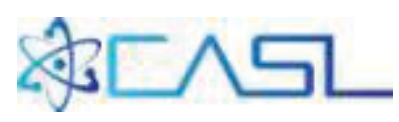

Figure 3.12. Prediction of experiment 3 (Table 3.1) with calibrated model.
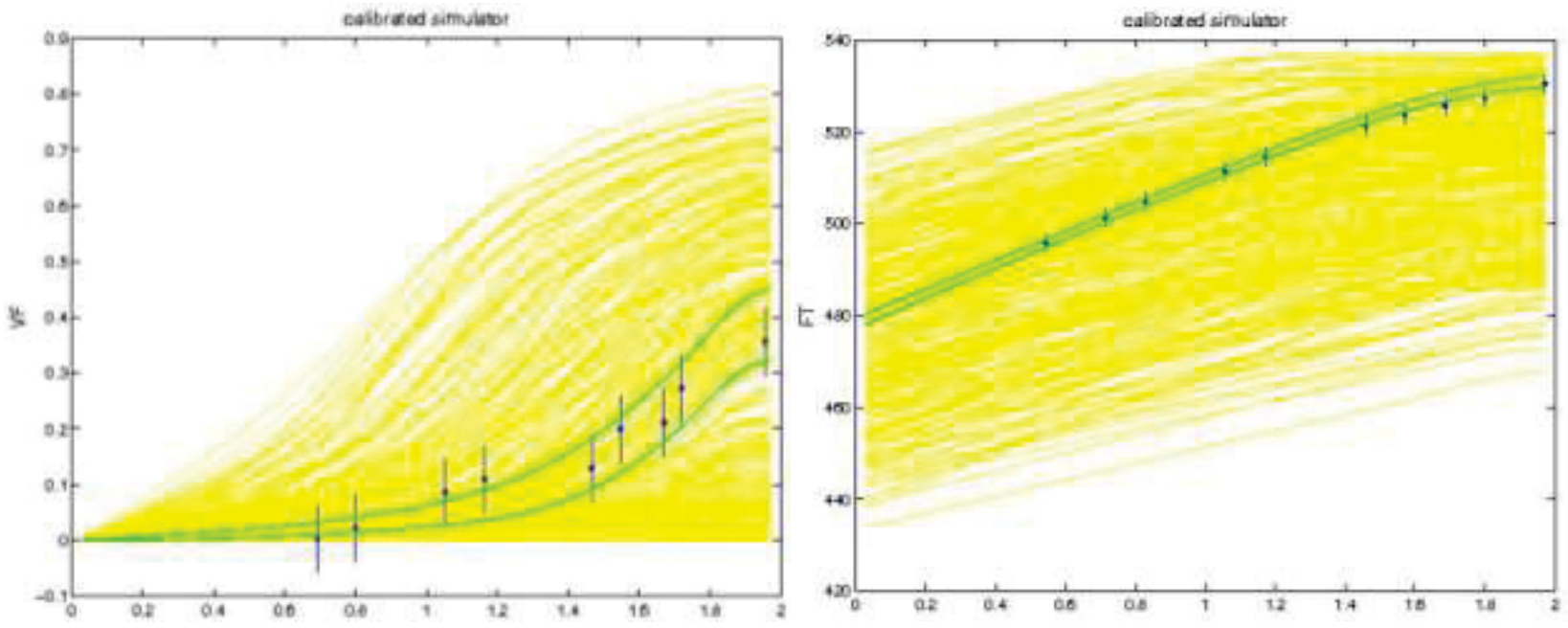

Figure 3.13. Prediction of experiment 4 (Table 3.1) with calibrated model.

Calibrated model predictions shown in Figures 3.10-3.13 were obtained by propagating posterior samples of parameters $\boldsymbol{\theta}$ (Figure 3.9) through the multivariate emulator $\boldsymbol{M}(\boldsymbol{x}, \boldsymbol{\theta})$ for each experimental condition given in Table 3.1. These predictions did not account for discrepancy, which was found to be relatively insignificant in a similar analysis by Bui et al. [51].

The calibration suggested that suitable parameters can be found that match the void fraction and fluid temperature data to within the assumed residual errors of 0.06 and 2.0, respectively.

It is constructive to note that application of this calibration approach to analysis of models of higher dimensionality (2D/3D) is straightforward without significant modification of GPM/SA.

\subsubsection{Calibration of SFB Model with Additional Data on Microphysics of Bubble Departure}

In this calibration, data on bubble departure diameter in addition to data on onedimensional (axial) void fraction and fluid temperature distributions were used. Data on bubble departure diameter are notably different from data on void fraction and fluid temperature distributions, since they are dependent on local subcooling temperature (not spatial location like void fraction and fluid temperature data). Data and simulations on bubble departure diameter were assumed to be conditionally independent of the void fraction and fluid temperature simulation data. An error standard deviation of $0.01 \mathrm{~mm}$ was assumed for the bubble departure diameter data.

Since functional data analysis with GPM/SA requires all the runs to be computed on a common grid of fixed variable values, a common grid of 35 local subcooling temperature was constructed from zero to the maximum local subcooling temperature observed in the simulations. The bubble departure diameters for each run were interpolated onto this grid via linear interpolation. For such a simple model of bubble departure diameter represented by Tolubinsky \& Konstanchuk's correlation, only four principal components (or eigenfunctions) (Figure 3.14) were needed to explain $99.9 \%$ of dispersion in the interpolated simulations of bubble departure diameter. 
The correlation lengths $\boldsymbol{\rho}_{\boldsymbol{\omega}}$ obtained for both bubble departure model parameters (shown in Figure 3.15) are near zero for PC's 2-4, suggesting that only variation in the coefficient of the dominant eigenfunction can be inferred from the simulation data.

The analysis indicated that additional data on bubble departure diameter can be successfully employed together with data on void fraction and fluid temperature distributions, leading to significantly less spreads in posterior distributions of the calibration parameters (Figure 3.16).

Calibrated model predictions obtained with the emulator and posterior samples of parameters are shown in Figures 3.17-3.21. Discrepancies were again not taken into consideration in these predictions due to their insignificance as noted in section 3.3.1.

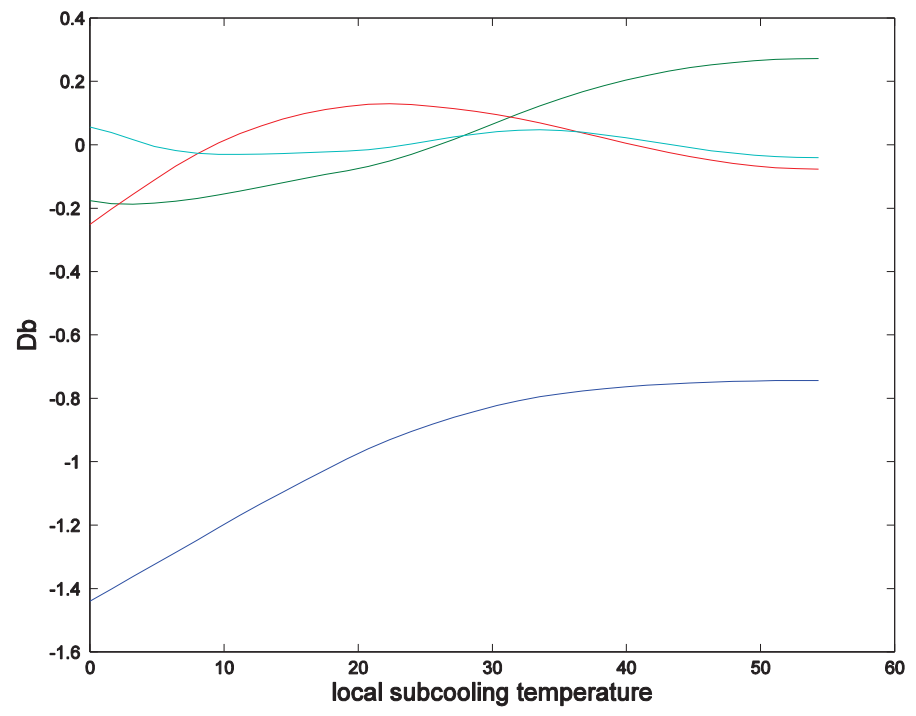

Figure 3.14. Variation of bubble departure diameter captured by 4 principal components (1-blue; 2-green; 3-red; 4-cyan).

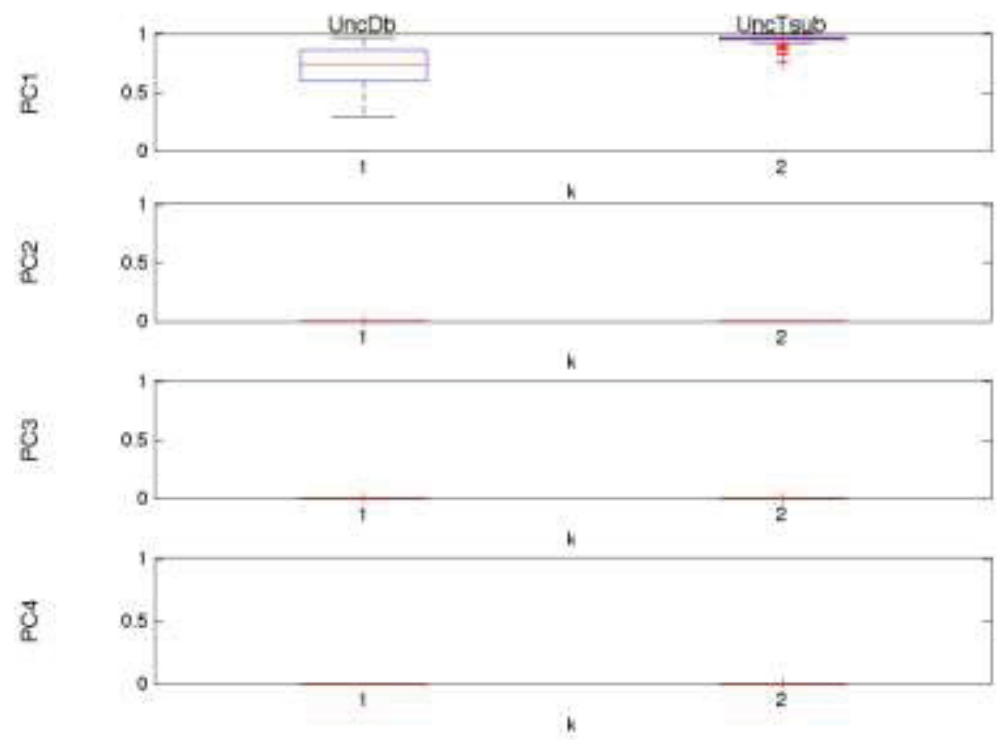

Figure 3.15. Boxplots of the marginal posterior distributions of correlation lengths $\boldsymbol{\rho}_{\boldsymbol{\omega}}$ parameters of the statistical model for $D_{d}$. 


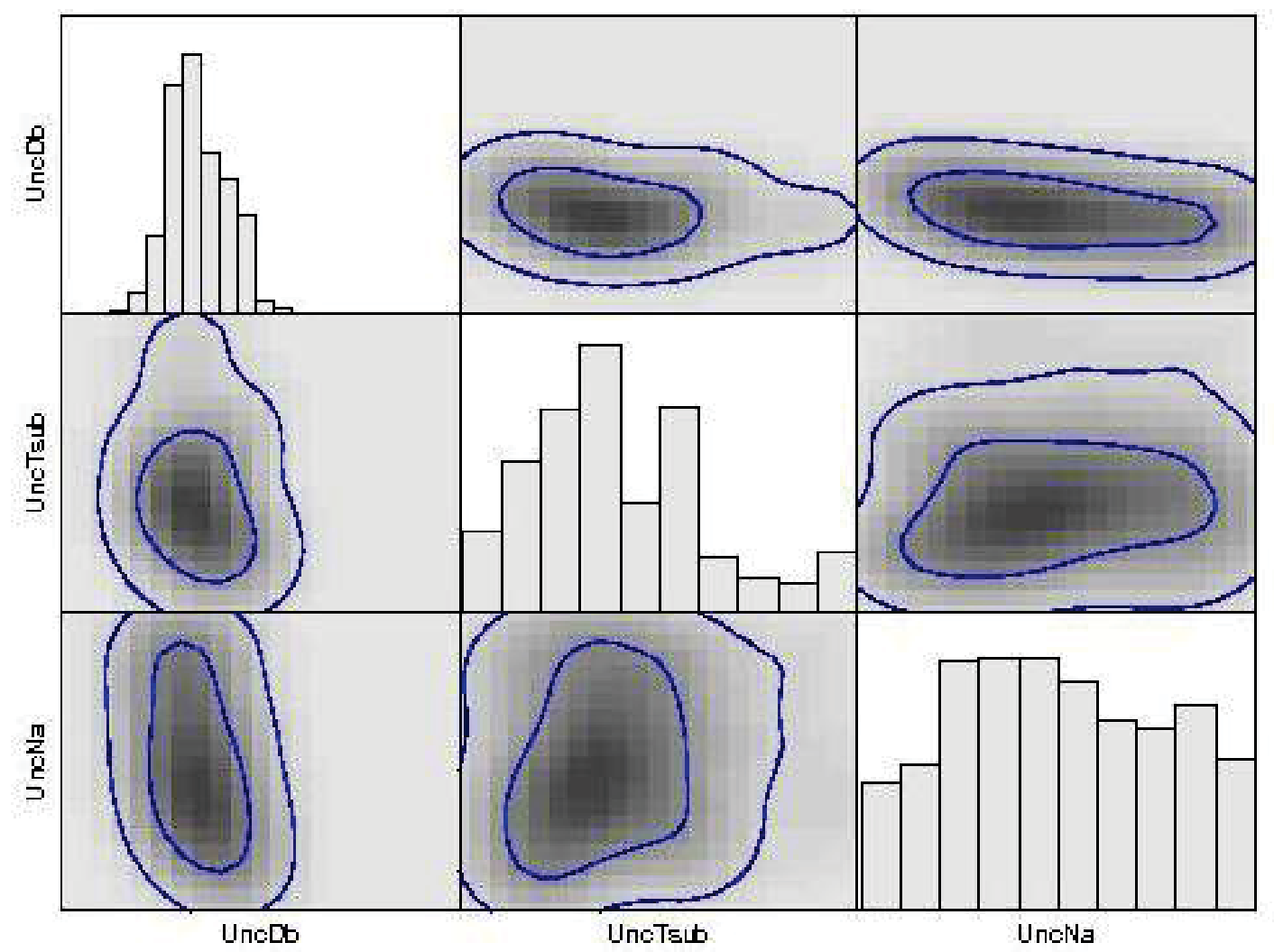

Figure 3.16. Posterior distributions of the calibration parameters.
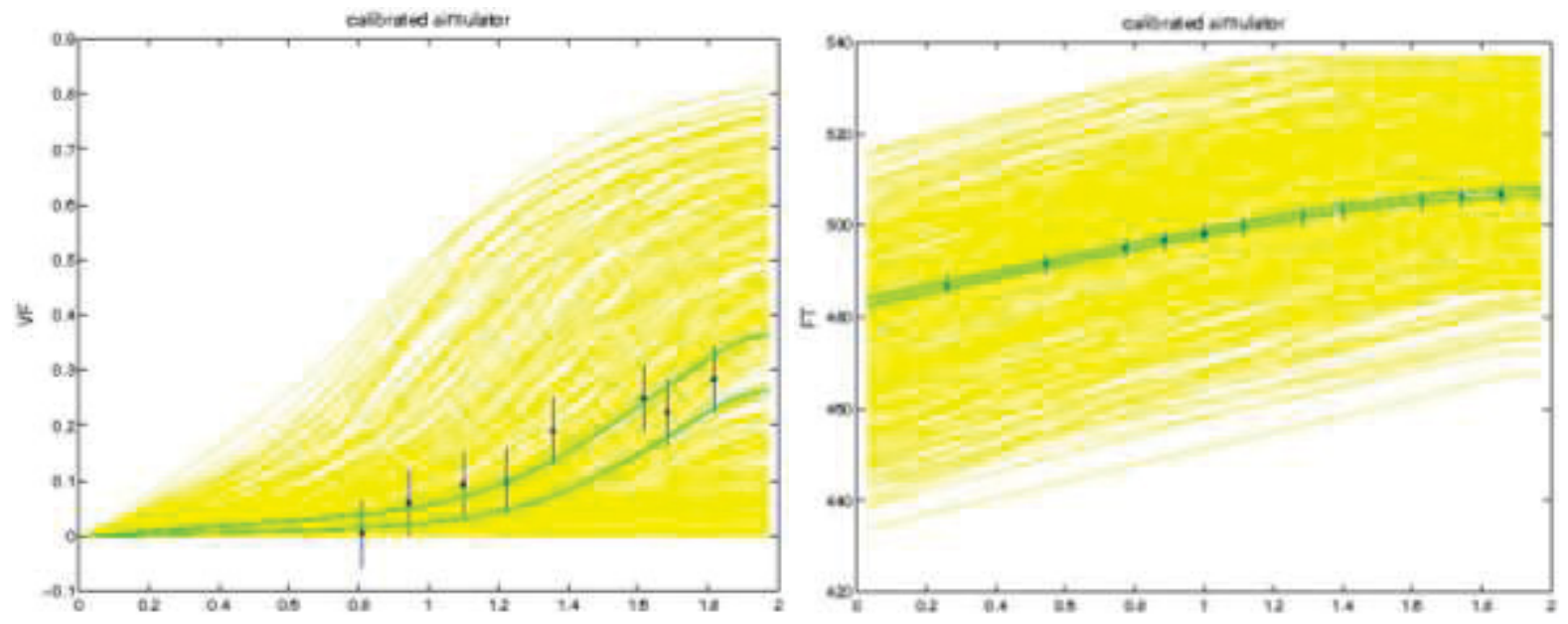

Figure 3.17. Prediction of experiment 1 (Table 3.1) with calibrated model. 


\section{㫌吃}

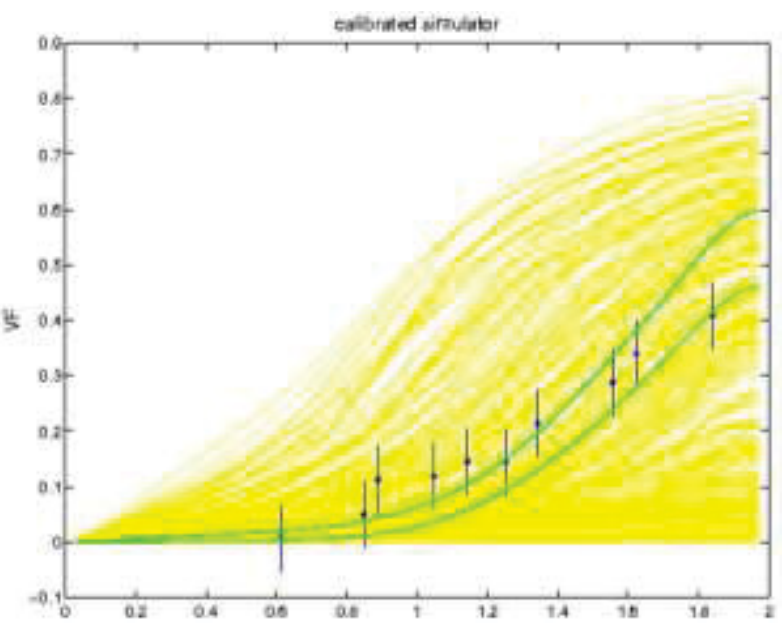

Figure 3.18. Prediction of experiment 2 (Table 3.1) with calibrated model.
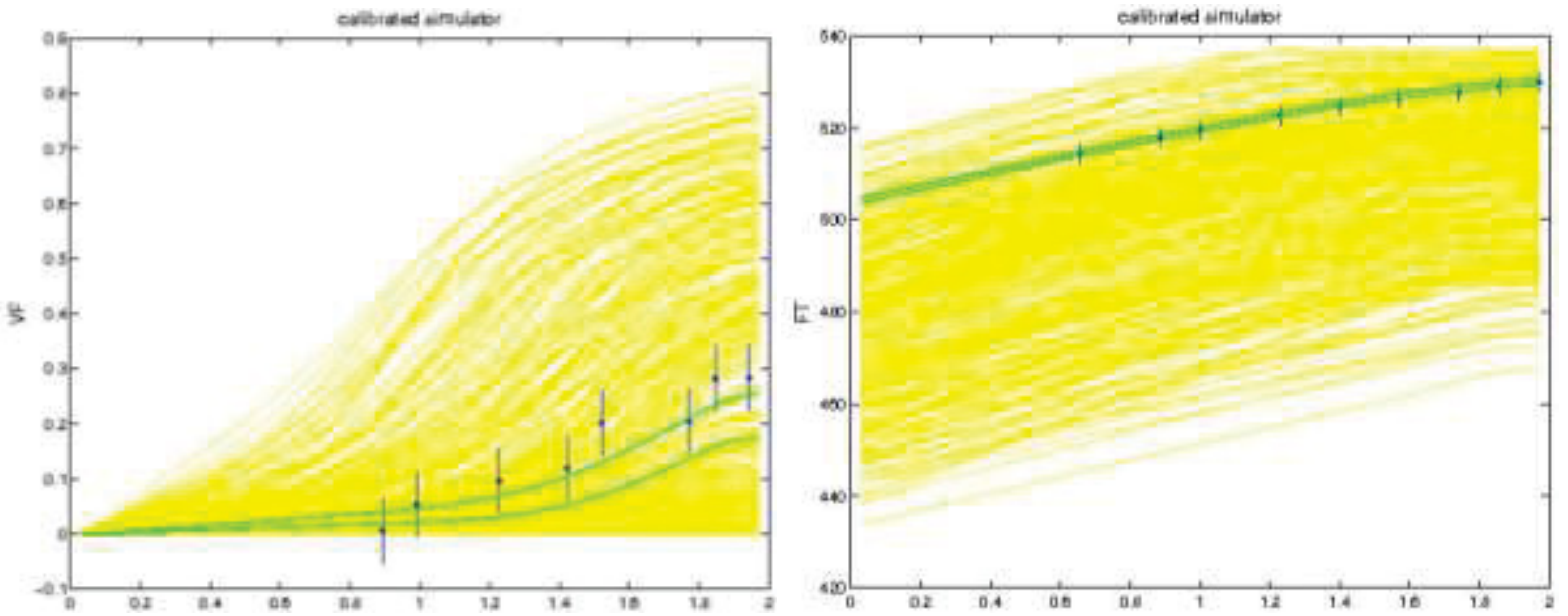

Figure 3.19. Prediction of experiment 3 (Table 3.1) with calibrated model.
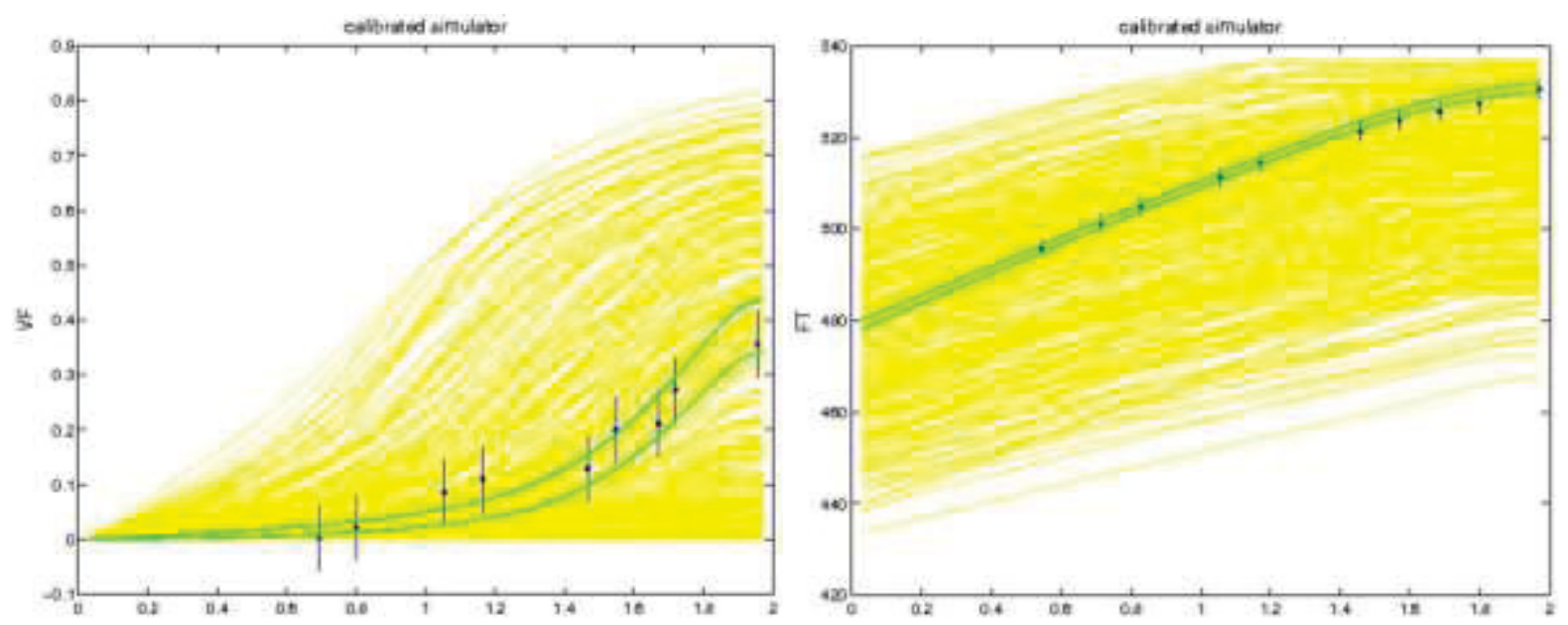

Figure 3.20. Prediction of experiment 4 (Table 3.1) with calibrated model. 


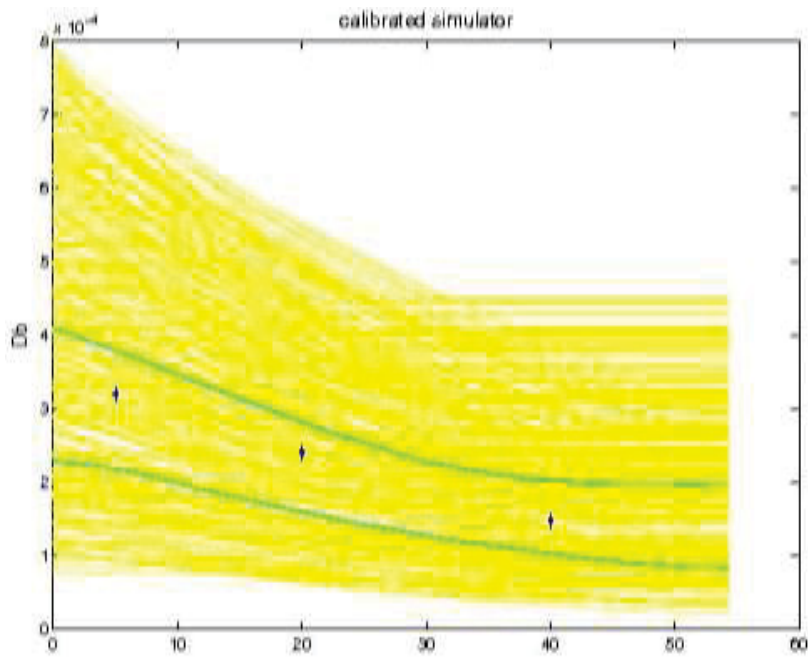

Figure 3.21. Prediction of bubble departure diameter with calibrated statistical model. Observed data are shown as blue dots with plus/minus one standard deviations $( \pm \sigma)$.

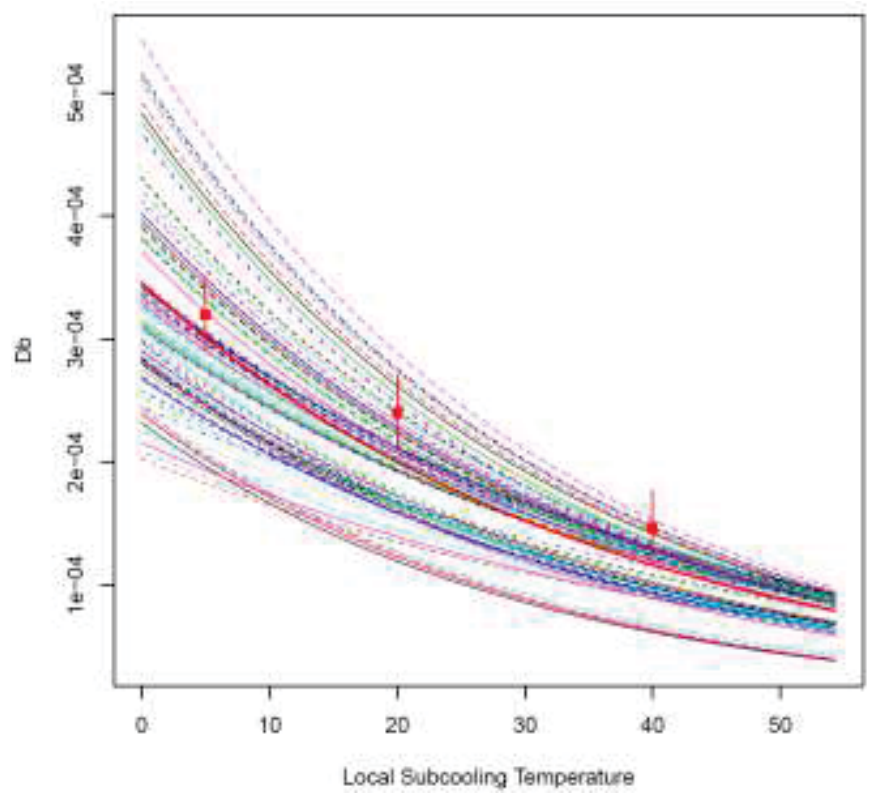

Figure 3.22. Spread of bubble departure diameter calculated with Tolubinsky \& Konstanchuk's correlation and calibrated parameters. Observed data are shown as red dots with plus/minus three standard deviations $( \pm 3 \sigma)$.

It is constructive to note that building of surrogate statistical models to represent simple models such as the bubble departure diameter model is not necessary, since they do not require excessive computational resources and times for evaluation and can be used directly in the calibration process.

\section{CONCLUSIONS AND RECOMMENDATIONS}

This report presents a sample calibration and validation of a realistic and relatively complex subcooled flow boiling model, which employed common approaches to modeling of the multiscale, multiphysics thermal hydrodynamics of two-phase flows with boiling and condensation. The SFB model utilized a description of multiphase flow as inter-penetrating continua with conservation laws applied to each phase as a separate field. Small-scale 
physics related to thermal hydrodynamic inter-phase and flow-wall interactions were represented by various empirical/semi-empirical closure sub-models. In this work, the submodel of wall evaporation, which relied on mechanistic descriptions of bubble growth/departure and wall nucleation, was calibrated.

In a departure from traditional (or common-sense) practice of tuning/calibrating complex models, a modern calibration technique based on statistical modeling and Bayesian inference was employed, which allowed simultaneous calibration of multiple sub-models (and related parameters) using different datasets. Quality of data (relevancy, scalability, and uncertainty) could be taken into consideration in the calibration process.

The proposed calibration technique would need tens thousands of model evaluations, which makes direct simulations by the original physical model impractical in many cases. A reduced-order model or a model surrogate is therefore needed. This study demonstrated that a surrogate (or emulator) of the SFB model with multidimensional and multivariate outputs could successfully be built using PCA, Gaussian processes, and process convolution method.

In a recognition of the heterogeneity of available validation data ("data realism" concept), effort was made to investigate the possibility of simultaneous assimilation/integration of different data types in complex model analysis. As demonstrated in this study, multidimensional/ multivariate data on large-scale distributions could be used in conjunction with data of small-scale physics for improved model calibration/validation in this preliminary realization of "total data-model integration" (TDMI) concept.

This exercise on SFB model development and implementation/application of advanced model calibration/validation method can potentially benefit CASL, because

- $\mathrm{SFB}$ is an important aspect of nuclear reactor thermal hydraulics and its accurate modeling is the objective of several CASL advanced simulation capabilities, such as COBRA-TF and Hydra-TH multiphase;

- CVUQ of CASL complex multiscale, multiphysics modeling capabilities can not purely rely on "traditional" techniques and there is a need for new approach which can leverage on all available data, account for validation data heterogeneity/ availability/quality, and provide a quantification of prediction uncertainty.

As pointed out in [1] and [2] a new validation data strategy/plan is needed to support this approach to calibration and validation of complex multiphysics models. This validation data strategy is of practical importance to CASL-wide VUQ efforts and entails, in particular:

- A comprehensive analysis of needs and collection and characterization requirements for CASL validation data;

- Establishment of a central validation database for warehousing of data from various sources (e.g. PIV, TC, imaging, SETs, IETs, DNSs, etc.), concerning various physics and scales (neutronics, thermal hydraulics, fuel behavior, structural mechanics), in different formats (table data, empirical correlations, etc.), and with estimates of measurement errors and uncertainty;

The calibration method demonstrated in this study is envisioned to be further developed and applied to more complex CASL VERA/VERA-CS modeling capabilities involving more physical models in the future. 


\section{REFERENCES}

[1] N. Dinh, "CIPS Validation Data Plan,” Tech. report, INL/EXT-12-25347, March 2012.

[2] A. Bui and N. Dinh, "Quantification of Data Needs, Data Collection and Characterization to Support Validation and Calibration of Subcooled Flow Boiling Model," Tech report INL/EXT13-28709, March 2013.

[3] N. Dinh, "CASL Validation Data: An Initial Review," Tech. report, INL/EXT-11-21017, Jannuary 2011.

[4] CASL, "Proposal for a Consortium for Advanced Simulation of LWRs," Oak Ridge National Laboratory, 2009.

[5] M. Kennedy and A. O'Hagan, "Bayesian calibration of computer models," J R Statist Soc B, vol. 63, pp. 425-464, 2001.

[6] M. Ishii and T. Hibiki, Thermo-Fluid Dynamics of Two-Phase Flow, Springer, 2011.

[7] N. Dinh, R. Nourgaliev and T. Theofanous, "Understanding the ill-posed two-fluid model," in NURETH-10, Seoul, Korea, 2003.

[8] M. Podowski, S. Antal, E. Tselishcheva and B. Wierzbicki, "Development of mechanistic models of two-phase flows for the NPHASE code," NRC Report NRC-04-03-048, 2007.

[9] R. Lahey Jr. and D. Drew, "The analysis of two-phase flow and heat transfer using a multidimensional, four field, two-fluid model," Nucl Eng Design, vol. 204, pp. 29-44, 2001.

[10] V. Stevanovic, S. Prica and B. Maslovaric, "Multi-Fluid Model Predictions of Gas-Liquid TwoPhase Flows in Vertical Tubes," FME Trans., vol. 35, pp. 173-181, 2007.

[11] M. Bonizzi, P. Andreussi and S. Banerjee, "Flow regime independent, high resolution multifield modelling of near horizontal gas-liquid flows in pipelines," Int J Multiphase Flows, vol. 35, pp. 34-46, 2009.

[12] T. Hibiki and M. Ishii, "One-dimensional drift-flux model and constitutive equations for relative motion between phases in various two-phase flow regimes," Int J Heat Mass Transfer, vol. 46, pp. 4935-4948, 2003.

[13] S. Elghobashi and T. Abou-Arab, "A two-equation turbulence model for two-phase flows," Phys Fluids, vol. 26, pp. 931-938, 1983.

[14] L. Bertodano, M. Jones and R. Lahey Jr., "Development of a k-e model for bubbly two-phase flow," J Fluids Eng, vol. 116(1), pp. 128-134, 1994.

[15] Y. Sato and K. Sekoguchi, "Liquid velocity distribution in two-phase bubble flow," Int J Multiphase Flow, vol. 2, pp. 79-95, 1975.

[16] D. Drew, "A turbulent dispersion force model for particles or bubbles," J Eng Mat, vol. 41, pp. 259-274, 2001.

[17] J. Riznic and M. Ishii, "Bubble number density and vapor generation in flashing flow," Int $J$ Heat Mass Transfer, vol. 32, pp. 1821-1833, 1989.

[18] G. Guido-Lavalle, P. Carrica, A. Clausse and M. Qazi, "A bubble number density constitutive equation," Nucl Eng Design, vol. 152, pp. 213-224, 1994.

[19] M. Ishii, S. Kim and J. Kelly, "Development of interfacial area transport equation," Nucl Eng Tech, vol. 37(4), pp. 525-536, 2005.

[20] W. Yao and C. Morel, "Volumetric interfacial area prediction in upward bubbly two-phase flow," Int J Heat Mass Transfer, vol. 47, pp. 307-328, 2004. 
[21] G. Yeoh and J. Tu, "Two-fluid and population balance models for subcooled boiling flow," Appl Math Modelling, vol. 30, pp. 1370-1391, 2006.

[22] G. Yeoh, S. Cheung, J. Tu and M. Ho, "Fundamental consideration of wall heat partition of vertical subcooled boiling flows," Int J Heat Mass Transfer, vol. 51, pp. 3840-3853, 2008.

[23] R. Rzehak and E. Krepper, "CFD for subcooled flow boiling: Parametric variations," Sci Tech of Nucl Installations, vol. 2013, pp. 1-22, 2013.

[24] B.-J. Yun, A. Splawski, S. Lo and C.-H. Song, "Prediction of a subcooled boiling flow with advanced two-phase flow models," Nucl Eng Design, vol. 253, pp. 351-359, 2012.

[25] S. Lo, A. Splawski and B. Yun, "The importance of correct modeling of bubble size and condensation in prediction of sub-cooled boiling flows," in Proc of NURETH-14, Toronto, Canada, 2011.

[26] B.-U. Bae, H.-Y. Yoon, D.-J. Euh, C.-H. Song and G.-C. Park, "Computational analysis of subcooled boiling flow with a one-group interfacial area transport equation," J Nucl Sci Tech, vol. 45(4), pp. 341-351, 2008.

[27] S. M. Ghiaasiaan, Two-phase flow, boiling and condensation in convertional and miniature systems, Cambridge University Press, 2008.

[28] S. Levy, Two-Phase Flow in Complex Systems, John Wiley \& Sons, 1999.

[29] "TRACE V5.0 THEORY MANUAL - Field Equations, Solution Methods, and Physical Models," US NRC.

[30] G. Guglielmini, E. Nannei and C. Pisoni, "Survey of Heat Transfer Correlations in Forced Covection Boiling," Thermo- and Fluid Dynamics, vol. 13, pp. 177-185, 1980.

[31] N. Agafonova, M. Gotovskii and I. Paramonova, "Comparative Analysis of Correlations for Calculating Subcooled Boiling Heat Transfer," Thermal Engineering, vol. 53, pp. 128-133, 2006.

[32] D. Drew, "Mathematical modeling of two-phase flow," Ann Rev Fluid Mech, vol. 15, pp. 261291, 1983.

[33] H. No and M. Kazimi, "The effect of virtual mass on the characteristics and the numerical stability in two-phase flows," MIT Energy Lab Report No. MIT-EL 81-023, 1981.

[34] N. Kurul and M. Podowski, "Multidimensional Effects in Forced Convection Subcooled Boiing," in Proc of the 9th Int Heat Transfer Conf, Jerusalem, Israel, 1990.

[35] V. Dhir, "Mechanistic Prediction of Nucleate Boiling Heat Transfer - Achievable or a Hopeless Task?," J Heat Transfer, vol. 128, pp. 1-12, 2006.

[36] G. Warrier and V. Dhir, "Review of experimental and analytical studies on low pressure subcooled flow boiling," in Proc of 5th ASME/JSME Joint Therm Eng Conf, San Diego, California, 1999.

[37] M. Podowski, "Toward mechanistic modeling of boiling heat transfer," Nucl Eng Tech, vol. 44(8), pp. 889-896, 2012.

[38] I. Shekriladze, "Boiling Heat Transfer: Mechanisms, Models, Correlations and the Lines of Future Research," Open Mech Eng J, vol. 2, pp. 104-127, 2008.

[39] T. Habiki and M. Ishii, "Active nucleation site density in boiling systems," Int J Heat Mass Transf, vol. 46, pp. 2578-2601, 2003.

[40] G. Kocamustafaogullari, "Pressure dependence of bubble departure diameter for water," Int Comm Heat Mass Transfer, vol. 10, pp. 501-509, 1983.

[41] N. Basu, G. Warrier and V. Dhir, "Wall heat flux partitioning during subcooled flow boiling: Part 1 - Model development," J Heat Transfer, vol. 127, pp. 131-140, 2005. 
[42] J. Klausner, R. Mei, D. Bernhard and L. Zeng, "Vapor bubble departure in forced convection boiling," Int J Heat Mass Transfer, vol. 36(3), pp. 651-662, 1993.

[43] R. Situ, T. Hibiki, M. Ishii and M. Mori, "Bubble lift-off size in forced convective subcooled boiling flow," Int J Heat Mass Transfer, vol. 48, pp. 5536-5548, 2005.

[44] S. Kutateladze and I. Gogonin, "Growth rate and detachment diameter of a vapour bubble in free convection boiling of saturated liquids," High Temperature, vol. 17, pp. 667-671, 1979.

[45] R. Surgue, "The Effects of Orientation Angle, Subcooling, Heat Flux, Mass Flux and Pressure on Bubble Growth and Detachment in Subcooled Flow Boiling," MIT Ms. Thesis, 2012.

[46] I. Asher, T. Drzewiecki, K. Fidkowski and T. Downar, "Parameter sensitivity study of boiling and two-phase flow models in computational thermal hydraulics," in Proc of NURETH-14, Toronto, Canada, 2011.

[47] T. Drzewiecki, I. Asher, T. Grunloh, V. Petrov, K. Fidkowski, A. Manera and T. Downar, "Parameter sensitivity study of boiling and two-phase flow models in CFD," J Comput Multiphase Flows, vol. 4(4), pp. 411-425, 2012.

[48] E. Krepper and R. Rzehak, "CFD for subcooled flow boiling: Simulation of DEBORA experiments," Nucl Eng Design, vol. 241, no. 9, pp. 3851-3866, 2011.

[49] P. Arendt, W. Chen and D. Apley, "Improving Identifiability in Model Calibration using Multiple Responses," in Proc of ASME 2011 Int Design Eng Tech \& Comp and Inf in Eng Conf, 2011.

[50] A. Bui and N. Dinh, "Validation Data Plan Implementation: Subcooled Flow Boiling Case Study,” Tech. report, INL/MIS-12-27303, September 2012.

[51] A. Bui, B. Williams, N. Dinh and R. Nourgaliev, "Statistical modeling support for calibration of a multiphysics model of subcooled boiling flows," in Proc of Int Conf Math Comput Methods Appl Nucl Sci Eng, Sun Valley, Idaho, 2013.

[52] G. Bartolomej and V. Chanturiya, "Experimental study of true void fraction when boiling subcooled water in vertical tubes," Thermal Engineering, vol. 14, pp. 123-128, 1967.

[53] G. Bartolomej, V. Brantov, Y. Molochnikov, Y. Kharitonov, V. Solodkii, G. Batashova and V. Mikhailov, "An experimental investigation of true volumetric vapour content with subcooled boiling in tubes," Thermal Engng, vol. 29, no. 3, pp. 132-135, 1982.

[54] J. Garnier, E. Manon and G. Cubizolles, "Local measurements on flow boiling of refrigerant 12 in a vertical tube," Multiphase Sci Tech, vol. 13, pp. 1-111, 2001.

[55] A. Rubin, A. Schoedel, M. Avramova, H. Utsuno, S. Bajorek and A. Velazquez-Lozada, "OECD/NRC Benchmark Based on NUPEC PWR Sub-channel and Bundle Tests (PSBT) Volume I: Experimental Database and Final Problem Specifications," OECD, 2012.

[56] G. Beitel, "Boiling heat-transfer processes and their application in the cooling of high heat flux devices," Tech. report, Calspan Corp./AEDC Operations, 1993.

[57] H. Auracher and M. Buchholz, "Experiments on the fundamental mechanisms of boiling heat transfer," J Braz Soc Mech Sci \& Eng, vol. 27, pp. 1-22, 2005.

[58] N. Basu, G. Warrier and V. Dhir, "Wall heat flux partitioning during subcooled flow boiling: Part II - Model validation," J Heat Transfer, vol. 127, pp. 141-148, 2005.

[59] G. Celata, M. Cumo and A. Mariani, "Experimental evaluation of the onset of subcooled flow boiling at high liquid velocity and subcooling," Int J Heat Mass Transfer, vol. 40, no. 12, pp. 2879-2885, 1997.

[60] N. Basu, G. Warrier and V. Dhir, "Onset of nucleate boiling and active nucleation site density during subcooled boiling," J Heat Transfer, vol. 124, pp. 717-728, 2002. 
[61] N. Dinh and T. Theofanous, "Nucleation phenomena in boiling," Multiphase Sci Tech, vol. 15, pp. 349-363, 2003.

[62] L. Zou, Experimental study on subcooled flow boiling on heating surfaces with different thermal conductivities, PhD Thesis, University of Illinois at Urbana-Champaign, 2010.

[63] M. Bartel, M. Ishii, T. Masuka, Y. Mi and R. Situ, "Interfacial area measurement in subcooled flow boiling," Nucl Eng Design, vol. 210, pp. 135-155, 2001.

[64] T.-H. Lee, R. Situ, T. Habiki, H.-S. Park, M. Ishii and M. Mori, "Axial development of interfacial area and void concentration profiles in subcooled boiling flow of water," Int J Heat Mass Transf, vol. 52, pp. 473-487, 2009.

[65] H. Ünal, "Maximum bubble growth time and bubble growth rate during subcooled nucleate boiling of water up to 17.7 MN/m2," Int J Heat Mass Transfer, vol. 19, pp. 643-649, 1976.

[66] R. Situ, M. Ishii, T. Habiki, J. Tu, G. Yeoh and M. Mori, "Bubble departure frequency in forced convection subcooled boiling flow," Int J Heat Mass Transf, vol. 51, pp. 6268-6282, 2008.

[67] S.-J. Kim and G.-C. Park, "Interfacial heat transfer of condensing bubble in subcooled boiling flow at low pressure," Int J Heat Mass Transfer, vol. 54, pp. 2962-2974, 2011.

[68] O. Zentoun, Subcooled flow boiling and condensation, $\mathrm{PhD}$ Thesis, McMaster University, Ontario, Canada, 1994.

[69] T. Theofanous, "The boiling crisis in nuclear reactor safety and performance," Int J Multiphase Flow, vol. 6, pp. 69-95, 1990.

[70] A. Olekhnovitch, A. Teyssedou and P. Tye, "Critical heat flux in a vertical tube at low and medium pressures. Part II - new data respresentation,” Nucl Eng Design, vol. 193, pp. 91-103, 1999.

[71] D. Hall and I. Mudawar, "Critical heat flux (CHF) for water flow in tubes-I.Compilation and assessment of world CHF data," Int J Heat Mass Transfer, vol. 43, pp. 2573-2604, 2000.

[72] S. Kandlikar, "Critical heat flux in subcooled flow boiling - an assessment of current understanding and future directions for research," Multiphase Sci Tech, vol. 13, no. 3, pp. 207232, 2001.

[73] X. Cheng and U. Muler, "Review of Critical Heat Flux in Water Cooled Reactors," Karlsruhe Research Center, 2003.

[74] V. Dhir, H. Abarajith and D. Li, "Bubble dynamics and heat transfer during pool and flow boiling," Heat Transfer Eng, vol. 28, pp. 608-624, 2007.

[75] I. Bolotnov and M. Podowski, "Modeling of gas/liquid flows using DNS," in Proc of 2011 ANS Annual Meeting, 2011.

[76] J. Gattiker, "Gaussian Process Models for Simulation Analysis (GPM/SA) - Command, Function, and Data Structure Reference," LANL report, 2008.

[77] B. Adams, W. Bohnhoff, K. Dalbey, J. Eddy, M. Eldred, D. Gay, K. Haskell, P. Hough and L. Swiller, "DAKOTA, A Multilevel Parallel Object-Oriented Framework for Design Optimization, Parameter Estimation, Uncertainty Quantificiation, and Senstivity Analysis: Version 5.0 Reference Manual," Sandia Tech Report SAND2010-2184, 2009,2010,2011,2013.

[78] I. Jolliffe, Principal Component Analysis, Springer, 2002.

[79] H. Lee, C. Holloman, C. Calder and D. Higdon, "Flexible Gaussian process via convolution," Duke University, 2002.

[80] D. Higdon, J. Gattiker, B. Williams and M. Rightley, "Computer model calibration using highdimension output," J American Statist Assoc, vol. 103, pp. 570-583, 2008.

[81] D. Higdon, M. Kennedy, J. Cavendish, J. Cafeo and R. Ryne, "Combining field data and 
computer simulations for calibration and prediction," SIAM J Sci Comput, vol. 26, pp. 448-466, 2004.

[82] "Gamma Distribution, Wikipedia," [Online]. Available: http://en.wikipedia.org/wiki/Gamma_distribution.

[83] W. Fuller, Measurement error models, John Wiley \& Sons, Inc., 1987. 